\title{
Mixed metal-antimony oxide nanocomposites: low pH water oxida- tion electrocatalysts with outstanding durability at ambient and ele- vated temperatures
}

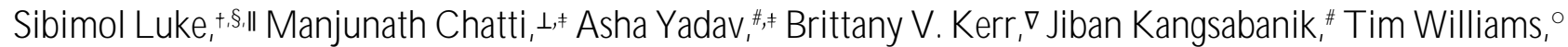 \\ Pavel V. Cherepanov, ${ }^{\perp}$ A kshat T anksale, II Bernt Johannessen, $\triangle$ D ouglas R. M acFarlane, ${ }^{\perp, I}$ \\ Rosalie K. H ocking,,$* *$ Aftab Alam,,$* *$ Aswani Yella,, ,** Alexandr N . Simonov ${ }^{\perp, 1, *}$ \\ + IIT B-M onash Research Academy, IIT Bombay, M umbai 400076, India \\ ${ }^{\S}$ D epartment of M etallurgical Engineering and M aterials Science, IIT Bombay, Powai, M umbai 400076, India \\ " Department of Chemical Engineering, M onash U niversity, Clayton, Victoria 3800, Australia \\ ${ }^{\perp}$ School of Chemistry, M onash University, Clayton, Victoria 3800, Australia \\ \# Department of Physics, IIT Bombay, Powai, M umbai 400076, India \\ $\nabla$ D epartment of C hemistry and Biotechnology, Swinburne U niversity of T echnology, H awthorn, Victoria 3800, Australia \\ M onash Centre for Electron M icroscopy, Clayton, Victoria 3800, A ustralia \\ $\triangle$ Australian Synchrotron, Clayton, Victoria 3168, Australia \\ ' ARC C entre of Excellence in Electromaterials Science, M onash U niversity, C layton, Victoria 3800, Australia
}

\begin{abstract}
ABST RACT : Electrochemical water splitting with a proton-exchange membrane electrolyte provides many advantages for the energy-efficient production of high-purity $\mathrm{H}_{2}$ in a sustainable manner, but the current technology relies on high loadings of expensive and scarce iridium at the anodes, which are also often unstable in operation. To address this, the present work scrutinises the electrocatalytic properties of a range of mixed antimony-metal ( $\mathrm{Co}, \mathrm{M} \mathrm{n}, \mathrm{N} \mathrm{i}, \mathrm{Fe}, \mathrm{Ru}$ ) oxides synthesised as thin films by a simple solution-based method for the oxygen evolution reaction in aqueous $0.5 \mathrm{M} \mathrm{H}_{2} \mathrm{SO}_{4}$. Among the noble-metal free catalysts, cobalt-antimony and manganese-antimony oxides demonstrate good stability over $24 \mathrm{~h}$ and reasonable activity at $24 \pm 2{ }^{\circ} \mathrm{C}$, but slowly lose their initial activity at elevated temperatures. The ruthenium-antimony system is highly active, requiring an overpotential of only $0.39 \pm 0.03$ and $0.34 \pm 0.01 \mathrm{~V}$ to achieve $10 \mathrm{~mA} \mathrm{~cm}{ }^{-2}$ at $24 \pm 2$ and $80^{\circ} \mathrm{C}$, respectively, and most importantly, remaining remarkably stable during one-week tests at $80^{\circ} \mathrm{C}$. D etailed characterisation reveals that the enhanced stability of metal-antimony oxides water oxidation catalysts can arise from two distinct structural scenarios: either formation of a new antimonate phase, or nanoscale intermixing of metal and antimony oxide crystallites. D ensity functional theory analysis further indicates that the stability in operation is supported by the enhanced hybridisation of the oxygen $p$ - and metal d-orbitals induced by the presence of $S b$.
\end{abstract}

\section{INTRODUCTION}

Water electrolysers based on a proton-exchange membrane (PEM) electrolyte are currently seen as the preferred technology for the production of green hydrogen from renewables. ${ }^{1-2}$ D ouble digit megawatt PEM plants are already available and even larger installations are planned. ${ }^{3}$ Recent breakthroughs in the design of bipolar plates and cathode catalysts for the PEM electrolysers now throw a spotlight on the membrane and anode electrocatalysts as the components requiring further significant cost-efficiency improvements. ${ }^{4}$ Catalysts for the oxygen evolution reaction (OER) are particularly problematic in essentially all key aspects - price, avai lability, activity and stability. While iridium oxides provide perhaps the best combination of the activity and stability among known monometallic catalysts, ${ }^{1}$ there is not enough of this exceptionally rare metal currently available to us to bring the PEM water electrolysis to the T W scale. ${ }^{5}$ Moreover, both theoretical and extensive experimental studies reveal the unavoidable degradation of iridium-based OER catalysts even under ambient conditions, ${ }^{6-10}$ and especially in industrially relevant high-temperature tests, ${ }^{11}$ which is among the reasons for the comparatively high loadings of I $\mathrm{in}$ the anodes of PEM electrolysers. Alternative $O E R$ catalysts based on more abundant and cheaper elements exist, in particular lead(IV)-based oxides developed through decades of research on the metal electrowinning anodes, ${ }^{12}$ though their specific activity is significantly lower than that of iridium systems..$^{13}$ Among other non-noble metal options, the obvious candidates are oxides of manganese, cobalt, nickel and iron, which have been widely investigated as $0 \mathrm{ER}$ catalysts for the alkaline and near neutral conditions. ${ }^{14-21} \mathrm{M}$ onometallic oxides of $\mathrm{M} n$ and $\mathrm{Co}$ have al so been examined for applications in acidic environment, and in contrast to $\mathrm{Ni}$ and Fe which immediately dissolve, ${ }^{22}$ relatively stable performance for several hours was demonstrated. ${ }^{23-24} \mathrm{H}$ owever, eventual degradation and essentially complete loss of activity is unavoidable. A noble alternative to iridium is also known - ruthenium oxides are reported to be at least as active OER catalysts. ${ }^{22}$ While the amount of Ru in the Earth's crust is only slightly higher than that of 
$\mid \mathrm{r}^{25}$ and it continues to rise in price, ruthenium is still morethan fivefold cheaper, ${ }^{26}$ is easier to refine and is produced on an order of magnitude higher scale. ${ }^{27} \mathrm{H}$ owever, rapid degradation of $\mathrm{RuO}_{2}$ anodes is again a major issue. ${ }^{28-30}$

O verall, it is highly unlikely that any monometallic oxide can provide an optimal combination of characteristics required to be a high-performance 0 ER catalyst. In contrast, new materials with improved activity and/ or stability emerge from the exploration of multielement oxide systems that sometimes combine the properties of individual compounds or exhibit distinct properties of their own. In the context of the design of catalysts for the low pH OER, successful approaches often emerge from combining a catalytically active oxide with the one that is highly stable under operating conditions to enable improved long-term operation with decreased losses in activity. This strategy has been broadly adopted for many years in the research on the electrowinning anode catalysts using $\mathrm{PbO}_{2}$ as a "matrix" that stabilises oxides of cobalt, manganese, silver and other metals. ${ }^{12,}{ }^{31-32}$ The same approach is now also applied in the design of anode cataIysts for PEM water electrolysers. I mproved electrochemical activity and durability during the $\mathrm{OER}$ in acidic solutions has been reported when catalytically active metals have been combined with the oxides of $\mathrm{Ta}^{\mathrm{IV}},{ }^{33-34} \mathrm{Sn}^{\mathrm{IV}},{ }^{34-35} \mathrm{Ti}^{\mathrm{iV}},{ }^{36-37} \mathrm{~Pb}^{\mathrm{IV}},{ }^{38-40} \mathrm{Y}^{\mathrm{III}},{ }_{4}^{41} \mathrm{Cr}^{\mathrm{IV}}$, ${ }^{42}$ and also $\mathrm{Sb}^{\mathrm{V}}$. 43-44

Antimony oxides $\left(\mathrm{SbO}_{x}\right)$ are of a particular interest in this context. The thermodynamic stability of $\mathrm{SbO}$ x under the low pH OER conditions, ${ }^{45}$ electrical conductivity, ${ }^{46-48}$ along with abundance and availability of $\mathrm{Sb}^{49}$ render these compounds a suitable structural component for acid-stable water oxidation electrocatalysts. Antimony oxides have been used as stabilising interlayers and components in robust electrowinning anodes, ${ }^{50-51}$ and have recently been also introduced to studies of OER catalysts for acidic water electrolysers. In particular, the research teams of G regoire ${ }^{44,52}$ and Lewis ${ }^{43,53}$ both reported promising activity and improved stability in operation of antimonates of manganese and nickel. More recent work also described cobalt antimonate OER catalysts. ${ }^{54}$ Thus, the stability of transition metal oxides during oxidation of acidic water can be improved viacombination with the highly promising $\mathrm{SbO}_{x}$ matrix. In the case of $\mathrm{Ru}$, this can also reduce the noble metal loading and thereby the cost. H owever, the catalysts of this type are currently underexplored and have only recently gained an increased attention.

In the search for highly active, and genuinely stable catalysts under practical operating conditions, the core aim of the present work is the investigation of the electrocatalytic activity and stability of mixed metal-antimony oxides towards the oxidation of acidic water. Specific emphasis is put on the stability, which is rarely assessed rigorously in the current literature, viz. the experiments are commonly limited to several hours and ambient temperature conditions only. M oreover, even such mild conditions cause continuous degradation of many catalysts, which sometimes remains underestimated when the stability data are recorded and presented in the galvanostatic mode. H erein, the initial tests were also undertaken under ambient conditions to identify the most promising catalysts, which were further investigated at elevated temperatures to assess and demonstrate the genuine suitability of antimony-metal oxides for operation under the conditions relevant to the PEM electrolysers. In-depth electrochemical and physical characterisation of the catalysts before and after exhaustive electrocatalytic tests coupled to the density functional theory (DFT) calculations reveal new insights into the origins of the stability of metal-antimony oxide $\mathrm{OER}$ catalysts on the structural and atomistic levels.

\section{RESULTS AND DISCUSSION}

All materials in this work were synthesised via annealing of precursor salts deposited from their solutions onto nominally flat glass supports covered with a thin conductive layer of $\mathrm{F}$-doped $\mathrm{SnO}_{2}$ (FTO). While sputtering and similar advanced techniques provide a better control over the morphology and composition, our choice over the much simpler drop-casting/ annealing fabrication protocol was motivated by the ease of the future optimisation of this approach for the creation of high-surface area catalysts of applied significance. All electrochemical tests were undertaken in $0.5 \mathrm{M} \mathrm{H}_{2} \mathrm{SO}_{4}$ with measured $\mathrm{pH}$ of 0.3 (at ambient temperature). All galvanostatic data are presented below after manual post-correction for ohmic losses using the uncompensated ( $R_{u}$ ) values measured by the electrochemical impedance spectroscopy. However, the correction was generally not applied to voltammograms, where currents cannot be always confidently attributed to the stationary catalytic process only. Extended details on the methods and procedures used in this work are provided in Supporting Information.

\section{Electrocatalytic activity under ambient conditions}

Individual metal oxides ( $\mathrm{MO} \mathrm{O}_{x}$ ) considered herein, viz. $\mathrm{RuO}_{x_{1}} \mathrm{CoO}_{x_{1}}$ $\mathrm{MnO}{ }_{x} \mathrm{~N} \mathrm{iO}_{x}$ and $\mathrm{FeO}_{x}$, as well as $\mathrm{SbO}_{x}$, werenot expected to be highperformance $0 \mathrm{ER}$ catalysts of independent interest, but their properties were briefly examined to understand relevant differences in the key performance parameters that are likely to affect those of the corresponding metal-antimony oxides. X-ray diffraction (XRD) and scanning electron microscopic (SEM) analysis of the as-prepared $\mathrm{MO} \mathrm{O}_{x}$ and $\mathrm{SbO}$ indicate that the materials were dominated by single oxide phases $\mathrm{RuO}_{2}, \mathrm{CO}_{3} \mathrm{O}_{4}, \mathrm{M} \mathrm{n}_{2} \mathrm{O}_{3}, \mathrm{NiO}, \mathrm{Fe}_{2} \mathrm{O}_{3}$, and $\mathrm{Sb}_{2} \mathrm{O}_{4}$ ( $\mathrm{Fig}$ ure S1) of variable morphology (Figure S2). Tests of $\mathrm{M} \mathrm{O}_{x}$ and $\mathrm{SbO}_{x}$ as $\mathrm{OER}$ catalysts confirmed their either limited stability $\left(\mathrm{RuO}_{2}\right.$, $\mathrm{CO}_{3} \mathrm{O}_{4}, \mathrm{NiO}$ and $\mathrm{Fe}_{2} \mathrm{O}_{3}$ ) or activity $\left(\mathrm{M} \mathrm{n}_{2} \mathrm{O}_{3}\right.$ and $\mathrm{Sb}_{2} \mathrm{O}_{4}$ ) (Figures $\mathrm{S}_{3}$ $\mathrm{S} 5$ and attached comments).

Further studies focused on mixed metal-antimony oxides, which are referred to as $[\mathrm{M}+\mathrm{Sb}] \mathrm{y}_{y}$. These catalysts were synthesised with a 1:1 molar metal:antimony precursor ratio, unless stated otherwise, but the actual composition during the $O E R$ is different due to the unavoidable corrosion in acidic solutions. The degree of this corrosion for the selected key materials was quantified ( Table 1 ) and is discussed later in the text.

Table 1. Relative loss of metals and antimony from catalysts (at.\%) ${ }^{\text {a }}$ during the $0 \mathrm{ER}$ in stirred $0.5 \mathrm{M} \mathrm{H}_{2} \mathrm{SO}_{4}$.

\begin{tabular}{|c|c|c|c|c|}
\hline \multirow[t]{2}{*}{ Catalyst } & \multicolumn{2}{|c|}{$24 \pm 2^{\circ} \mathrm{C}^{b}$} & \multicolumn{2}{|c|}{$80^{\circ} \mathrm{C}^{\mathrm{C}}$} \\
\hline & M etal & $\mathrm{Sb}$ & M etal & $\mathrm{Sb}$ \\
\hline$[\mathrm{Mn}+\mathrm{Sb}] \mathrm{O}_{y}$ & 21 & 17 & \multirow{2}{*}{\multicolumn{2}{|c|}{$\mathrm{N}$ ot analysed }} \\
\hline$[\mathrm{Co}+\mathrm{Sb}] \mathrm{O}_{y}$ & 15 & 26 & & \\
\hline$[\mathrm{Ru}+\mathrm{Sb}] \mathrm{O}_{y}$ & 1 & 37 & 3 & 47 \\
\hline
\end{tabular}

${ }^{a} C$ alculation based on the amount of metal and $\mathrm{Sb}$ deposited onto electrodes $\left(1 \mu \mathrm{mol} \mathrm{cm}{ }^{-2}\right.$ each) and the amounts measured in solutions after the 0 ER tests by ICP-O ES. ${ }^{b} 10 \mathrm{~mA} \mathrm{~cm}^{-2}$ for $24 \mathrm{~h}$ and then 2.03 and 1.93 $\mathrm{V}$ vs. RHE for $0.5 \mathrm{~h}$ at each potential. ${ }^{\mathrm{c}} 10 \mathrm{~mA} \mathrm{~cm}^{-2}$ for $192 \mathrm{~h}$ and then 2.03 and $1.93 \mathrm{~V}$ vs. RHE for $0.5 \mathrm{~h}$ at each potential.

First, we exclude $\mathrm{N}$ i- and Fe-based systems from detailed analysis, as these materials rapidly degraded under the $0 E R$ conditions ( $F$ igure $\mathrm{S} 6$ and S7). Attempts to improve their performance through variations in the metal : antimony ratios and annealing temperature were not successful. The effect of the latter parameter was also briefly 
considered for the much better performing $\mathrm{Co}-, \mathrm{M} \mathrm{n}$ - and $\mathrm{Ru}-\mathrm{Sb}$ oxidecatalysts. T he best results were always obtained at $600{ }^{\circ} \mathrm{C}$ (Figure S8), which is the highest value we could use due to thermal instability of FTO ${ }^{55} \mathrm{H}$ ence, all results discussed here in the main text of the paper were obtained with the catalysts synthesised at $600^{\circ} \mathrm{C}$.

Voltammetric assessment of the initial OER catalytic activity of $\mathrm{CoO} x$ and $[\mathrm{Co}+\mathrm{Sb}] \mathrm{O}_{y}$ revealed lower performance of the latter ( Figure S3a and 1a), which is likely associated with the reduced amount of the active cobalt oxide surface species, as also measured by cyclic voltammetry ( $c f$. Figures S5a and S9a). Subsequently recorded chronopotentiograms reveal the significant initial degradation of the cobalt-antimony-modified electrode, though more importantly [Co+Sb]O y catalysts do not completely lose their activity and sustain a current density of $10 \mathrm{~mA} \mathrm{~cm} \mathrm{~cm}^{-2}$ at a reasonable overpotential (Figure 1b). The duration of the initial drop increased with an increase in the $\mathrm{Co}: \mathrm{Sb}$ ratio used for the synthesis, while the best stabilised activity was demonstrated by the catalysts prepared with equimolar amounts of $\mathrm{Co}$ and $\mathrm{Sb}$ (Figure S10). This type of [C $+\mathrm{Sb}] 0$ y demonstrated stable water oxidation at $10 \mathrm{~mA} \mathrm{~cm}{ }^{-2}$ at a well-reproducible $I R_{u}$-corrected overpotential of $0.769 \pm 0.010 \mathrm{~V}$ (Figures $1 \mathrm{~b}$ and S11). Subsequent potentiostatic tests at 2.03 and $1.93 \mathrm{~V}$ vs. RHE also did not reveal further significant losses in the catalytic activity (Figure 1c). A plausible explanation of the rapid initial loss of the performance is provided in the following section, while at this stage we conclude that $[\mathrm{Co}+\mathrm{Sb}] \mathrm{O}_{y}$ exhibitsa reasonable short-term stability during the $\mathrm{OER}$ at low $\mathrm{pH}$ and ambient temperature, yet its catalytic activity is not high.

In contrast to the cobalt-based materials, combination of $\mathrm{Mn}$ with $\mathrm{Sb}$ produced a very significant improvement in the $O E R$ catalytic activity with respect to monometallic $\mathrm{MnO}_{x}$ ( Figure $\mathrm{S} 3 \mathrm{~b}$ and $1 \mathrm{la}$ ). The $[\mathrm{M}+\mathrm{Sb}] \mathrm{O}$ y catalysts were also able to maintain the initial performance during $24 \mathrm{~h}$ galvanostatic tests ( Figure $1 \mathrm{~b}$ ). Variations in the $\mathrm{Mn}$ to $\mathrm{Sb}$ precursor ratio revealed that the manganese-rich materials ( $\mathrm{Mn}: \mathrm{Sb}=2: 1$ ) suffer slow deterioration in performance ( Figure $\mathrm{S12}$ ), which was also recently reported for $\mathrm{Mn}$ antimonate with a similar starting composition and under comparable conditions. ${ }^{52}$ Contrasting this behaviour, the activity of $[\mathrm{Mn}+\mathrm{Sb}] \mathrm{O}$ y synthesised herein with $1: 1$ and $1: 2$ ratios was highly stable. Between these two types of materials, the $S b$-rich one was found to be less active, exhibiting $\eta$ R for $10 \mathrm{~mA} \mathrm{~cm}{ }^{-2}$ of ca $0.70 \mathrm{~V}$. The best-performing $[\mathrm{Mn}+\mathrm{Sb}] \mathrm{O}$ y electrocatalysts with the initial equimolar $\mathrm{Mn}: \mathrm{Sb}$ ratio stably maintain the $O E R$ current density of $10 \mathrm{~mA} \mathrm{~cm}^{-2}$ for at least 24 hours under ambient conditions at a highly reproducible overpotential of $0.677 \pm 0.008 \mathrm{~V}$ (Figures $1 \mathrm{~b}$ and S13).

Combination of ruthenium with the antimonate matrix produced catalysts that exhibit a stable cyclic voltammetric response typical of

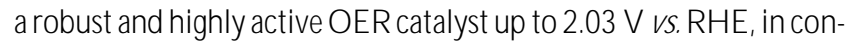
trast to unstable RuO ${ }_{x}$ (Figures 1a, S3e and S6e). M oreover, galvanostatic tests at $10 \mathrm{~mA} \mathrm{~cm}^{-2}$ improved the performance of the [Ru+Sb] 0 y materials by $c a 0.04 \mathrm{~V}$ over the initial $c a 10-12 \mathrm{~h}$ of experiments, eventuating in a reproducible stabilised $I R_{u}$-corrected overpotential of $\eta$ IR $=0.39 \pm 0.03 \mathrm{~V}$ (Figures $1 \mathrm{~b}$ and S14).

$O$ verall, the analysis of the initial catalytic performance and $25 \mathrm{~h}$ stability at ambient temperature of the metal-antimony oxides revealed a synergistic effect of the combination of a catalytically active metal and acid-stable $\mathrm{Sb}$ for the $[\mathrm{Mn+Sb}] \mathrm{O}_{\text {y }}$ system, where a significant improvement in the activity was achieved. The key advantage of combining $\mathrm{C} O$ and $\mathrm{Ru}$ with the $\mathrm{SbO}{ }_{x}$ matrix is in the substantial improvements in the stability, which is a highly favourable outcome given that the instability of the $O E R$ anode catalysts is among the most technologically pressing problems of the PEM water electrolysers. ${ }^{56}$
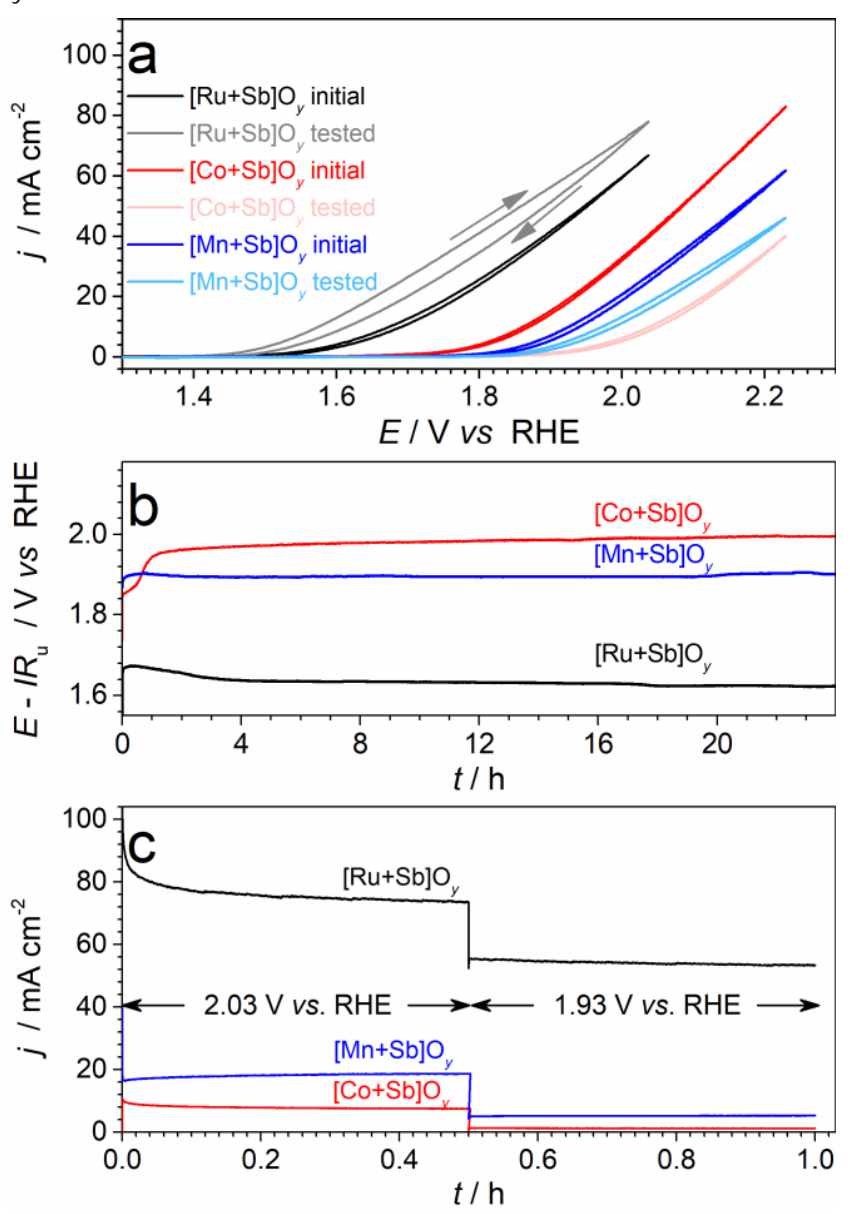

Figure 1. Electrochemical characterisation of $\left[\mathrm{Co}+\mathrm{Sb}_{0} \mathrm{O}_{y}\right.$ ( red), $[\mathrm{Mn}+\mathrm{Sb}] \mathrm{O}_{y}$ (blue) and [Ru+Sb] ${ }_{y}$ (black) in stirred $0.5 \mathrm{M} \mathrm{H}_{2} \mathrm{SO}_{4}$ at $24 \pm 2{ }^{\circ} \mathrm{C}$ : (a) cyclic voltammetry ( scan rate $0.020 \mathrm{~V} \mathrm{~s}^{-1}$; third scans; no $I R_{u}$ correction applied) recorded before (vivid traces) and after (pale traces) tests shown in panels $b$ and $c$ ( arrows exemplify the direction of the voltammetric sweeps, which was qualitatively the same for all catalysts); (b) $I R_{u}$-corrected chronopotentiograms (current density $10 \mathrm{~mA}$ $\mathrm{Cm}^{-2}$ geom.); and (c) subsequently recorded chronoamperograms (at a non- $/ R_{u}$-corrected potentials of 2.03 and $1.93 \mathrm{~V}$ vs. RHE).

\section{Characterisation of the mixed metal-oxide catalysts}

To enable deeper understanding of the observed trends in the electrocatalytic performance of the investigated metal-antimony oxides, physical characterisation of the key materials was undertaken using the state-of-the-art techniques.

Corrosion during operation. SEM images of the $[M+S b] 0$ y electrodes taken before and after the $O E R$ tests revealed that the initially flat, essentially featureless catalyst coatings underwent partial erosion due to the loss of material during the OER (Figure S15). The level of this loss was quantified for the key catalysts by ICP-OES ( T able 1), while the changes in the catalyst surface compositions were estimated by X-ray photoelectron spectroscopy (XPS).

After $24 \mathrm{~h}$ galvanostatic followed by $1 \mathrm{~h}$ potentiostatic tests at ambient temperature, the levels of corrosion of metals and antimony from $[\mathrm{Co}+\mathrm{Sb}] \mathrm{O}_{y}$ and $[\mathrm{Mn}+\mathrm{Sb}] \mathrm{O}_{y}$ into the electrolyte solutions were comparable ( $T$ able 1 ), notwithstanding a very distinct electrocataIytic behaviour ( Figure 1). XPS showed that concentrations of the 
metals at the surface of tested [ $\mathrm{Co}+\mathrm{Sb}] 0$ and $[\mathrm{Mn}+\mathrm{Sb}] \mathrm{O}_{y}$ werealso similar ( $T$ able 2). At the same time, voltammetric analysis, which provides the only reliable means of probing the catalytically active species, indicated that [ $\mathrm{Mn+Sb}] \mathrm{O}_{y}$ still exhibit detectable peaks associated with $M n$ redox transformations after the OER (Figure $\mathrm{S} 8 \mathrm{~b})$, while operated $[\mathrm{C} \mathrm{O}+\mathrm{Sb}] \mathrm{O}_{y}$ present a featureless response (Figure S8a). These observations might reflect the differences in the quasi-stabilised concentrations of the catalytically active metals in the top-most layers of the $\mathrm{Co}-\mathrm{Sb}$ and $\mathrm{M} \mathrm{n}$-Sb oxide systems. While the $[\mathrm{Co}+\mathrm{Sb}] \mathrm{O}_{\text {y }}$ surface loses a very significant part of its cobalt, $[\mathrm{Mn}+\mathrm{Sb}] \mathrm{O}_{y}$ is likely to maintain a higher amount of manganese available for the $O E R$ catalysis.

Table 2. Relative surface concentrations of metals for catalysts ${ }^{\mathrm{a}}$
before and after OER tests in stirred $0.5 \mathrm{M} \mathrm{H}_{2} \mathrm{SO}_{4}$.
\begin{tabular}{llll} 
Catalyst & As prepared & \multicolumn{1}{c}{ Tested at } \\
\cline { 2 - 4 } & & $24 \pm 2{ }^{\circ} \mathrm{C}^{\mathrm{b}}$ & $80^{\circ} \mathrm{C}^{\mathrm{c}}$ \\
{$[\mathrm{Mn}+\mathrm{Sb}] 0_{y}$} & $23 \pm 1$ & $12 \pm 2$ & n.a. \\
{$[\mathrm{Co}+\mathrm{Sb}] 0_{y}$} & $34 \pm 2$ & $9 \pm 4$ & n.a. \\
{$[\mathrm{Ru}+\mathrm{Sb}] 0_{y}$} & $9 \pm 5$ & n.a. & $44 \pm 5$
\end{tabular}

a at.\% with respect to total metal + antimony amount quantified by XPS; data are presented as a mean \pm one standard deviation for several measurements. ${ }^{b} 10 \mathrm{~mA} \mathrm{~cm}^{-2}$ for $24 \mathrm{~h}$ and 2.03 and $1.93 \mathrm{~V}$ vs. RHE for $0.5 \mathrm{~h}$ at each potential. ${ }^{\mathrm{c}} 10 \mathrm{~mA} \mathrm{~cm} \mathrm{~cm}^{-2}$ for $10 \mathrm{~h}$.

The lowest level of metal corrosion was observed for [Ru+Sb] $y$ where the amount of lost ruthenium was not more than 1 at.\% at ambient temperature, but the amount of antimony released into the electrolytesolution was significant ( $T$ able 1). T his was accompanied by a slight increase in the pre-catalytic voltammetric currents (Figure S9e). M ost critically, long-term tests of [ Ru+Sb] $0_{y}$ at elevated temperature of $80^{\circ} \mathrm{C}$ ( vide infra) caused only slightly higher level of corrosion ( $T$ able 1), while XPS consistently demonstrated that the surface Ru : Sb ratio increased up to ca 1:1 (Table 2). Thus, [Ru+Sb] $0_{y}$ suffers a favourable corrosion of antimony that improves the electrocatalytic activity of the material towards the OER (Figures $1 b$ and $2 a$ ) through an enrichment of the surface layer in catalytically active ruthenium.

When considered together, the observed levels of corrosion ( $T$ ables 1 and 2) and stable electrocatalytic performance of the manganese-, cobalt- and ruthenium-antimony oxides (except for the initial drop in the $[\mathrm{Co}+\mathrm{Sb}] \mathrm{O}_{y}$ performance) (Figure 1) suggest that a quasiequilibrium between the solid oxides and dissolved forms of $\mathrm{M} \mathrm{n} / \mathrm{Co} / \mathrm{Ru}$ and $\mathrm{Sb}$ is established in the system. Such an equilibrium between dissolution/ redeposition of metal oxides is likely to sustain the observed stable electrocatalytic operation. In other words, the examined OER catalysts most probably operate in a self-healing mode, ${ }^{38-39,57-59}$ with the Sb oxide matrix acting to facilitate the redeposition and suppress the dissolution of the active component.

Structural features. The structural features and the oxidation states of metals and antimony in the key $[\mathrm{Co}+\mathrm{Sb}] \mathrm{O}_{y_{1}}[\mathrm{Mn}+\mathrm{Sb}] \mathrm{O}_{y}$ and [Ru+Sb] $0_{y}$ samples were probed by XAS (Figure 2), XPS (Figures S16-S18) and XRD (Figure 3). The ruthenium-antimony system was additionally investigated by T EM (Figure 4).

Fitting of the $\mathrm{Sb} 3 \mathrm{~d}+0$ 1s spectra and comparisons to the literature ${ }^{60-61}$ confirmed that antimony adopts a dominant oxidation state $5+$ in all catalysts after the OER tests, as well as in most of the untreated samples ( Figure S16). The Sb K-edge XANES recorded for $\mathrm{Mn-}, \mathrm{C}$ o- and Ru-Sb mixed oxides reproduced well the data reported elsewhere for manganese antimonates, ${ }^{52}$ and are again consistent with the 5+ state (Figure 2a and S19) . A slight shift to higher energy was noted in the Sb K-edge after the O ER tests ( Figures S19). Sb Kedge EXAFS of the investigated metal-antimony oxides are similar to each other and to $\mathrm{Sb}_{2} \mathrm{O}_{5}$ in that none of the datasets exhibit any notable second coordination sphere peaks in the Fourier T ransform (FT) of EXAFS beyond the first coordination sphere apparent distances ( $\left.R^{\prime}\right)$ of $2 \AA$ (Figures 2a and S20). This would be consistent with $\mathrm{Sb}$ being present as a part of a highly-disordered phase or might be the consequence of how the distances in the structure cancel each other out (Figure S20 and T able S1).

The shape and position of the $M n 2 p_{5 / 2}$ peaks for fresh [ $\left.M n+S b\right] O_{y}$ are similar to those for the oxide/ oxyhydroxide $\mathrm{M} \mathrm{n}^{3+}$ compounds, ${ }^{62}$ and show only a slight shift towards higher binding energies after tests ( FigureS17a). Comparisons of the $\mathrm{M} n \mathrm{~K}$-edgeXAN ES datafor [ $\mathrm{M} \mathrm{n+Sb}] \mathrm{O}_{y}$ to that for the $\mathrm{M} \mathrm{nO}, \mathrm{M} \mathrm{n}_{2} \mathrm{O}_{3}$ and $\mathrm{M} \mathrm{nO}_{2}$ standards suggest that the oxidation state of the metal in the bulk of the as-prepared material is between $2+$ and $3+$, while $\mathrm{M} \mathrm{n}^{3+}$ becomes a dominant component after the OER tests (Figures $2 \mathrm{~b}$ and S21).

The Co K-edge XANES of as-prepared [ $\mathrm{Co}+\mathrm{Sb}] \mathrm{O}_{y}$ is consistent with an oxidation state between $2+$ and $3+$, or a material like $\mathrm{C}_{3} \mathrm{O}_{4}$ (Figure $2 \mathrm{C}$ ). The $\mathrm{Co} \mathrm{K}$ pre-edge intensity decreases after the $\mathrm{OER}$ test, which would be consistent with theloss of the $\mathrm{C}_{3} \mathrm{O}_{4}$ phase with a tetrahedral $\mathrm{CO}^{2+}$ site (Figure S22a-b), which is also supported by changes in the XANES profile (Figure $2 \mathrm{C}$ ). The major $\mathrm{Co}$ oxidation state on the surface can be also ascribed to 3 +based on the XPS analysis (Figure S17b) and comparisons to the literature. ${ }^{62}$

Thus, both XPS and XANES indicate that the dominating oxidation states of manganese and cobalt in as-prepared metal-antimony mixed oxides are between $2+$ and $3+$. Although $\mathrm{Mn}$ and $\mathrm{Co}$ at the catalytic surfaces likely adopt higher oxidation states during the $O E R$, those cannot be detected by ex situ analysis due to their very high oxidative reactivity and immediate conversion into states that are thermodynamically favourable under ambient environment. ${ }^{63-65}$

$X$-ray diffractograms of [ $\mathrm{Co}+\mathrm{Sb}] \mathrm{O}_{y}$ and $[\mathrm{Mn}+\mathrm{Sb}] \mathrm{O}_{y}$ exhibited a set of peaks typical of a tetragonal trirutile phase with major 110,013 and 123 reflections at ca27, 35 and 53, respectively (Figure 3a-b). Q ualitatively similar XRD patterns were obtained for the mixed nickel-antimony and iron-antimony samples (Figure S23). These data agree with the recent studies, ${ }^{43,52,54}$ and formally suggest that the metal-antimony phase in the investigated materials is structurally similar to $\mathrm{CoSb}_{2} \mathrm{O}_{6}$. It is also worth noting that the mean crystallite sizes for the individual metal oxides phases detected by XRD were notably higher than those for the antimonate phase ( Figure 3a-b), suggesting that the former are present as larger agglomerates as compared to the latter and therefore make significantly lower contribution to the electrocatalytically active surface area.

Well-defined FT EXAFS beyond the first coordination sphere were observed at the metal $\mathrm{K}$-edges for [ $\mathrm{Co}+\mathrm{Sb}] \mathrm{O}_{y}$ and [ $\left.\mathrm{M} \mathrm{n}+\mathrm{Sb}\right] \mathrm{O}_{y}$ ( Figure $2 b-c)$. This indicates that the metals do not simply dope the antimony oxide lattice, as was observed previously for the conceptually similar $\mathrm{C} 0-\mathrm{Fe}$-Pb oxide $\mathrm{O}$ ER catalyst, ${ }^{38}$ and more complicated structural scenarios apply. To describe the metal-antimony phases, EXAFS simulations based on the crystal structure of $\mathrm{M} \mathrm{nSb}_{2} \mathrm{O}_{6}{ }^{66}$ and that of $\mathrm{C} \mathrm{OSb}_{2} \mathrm{O}_{6}{ }^{67}$ were undertaken. 

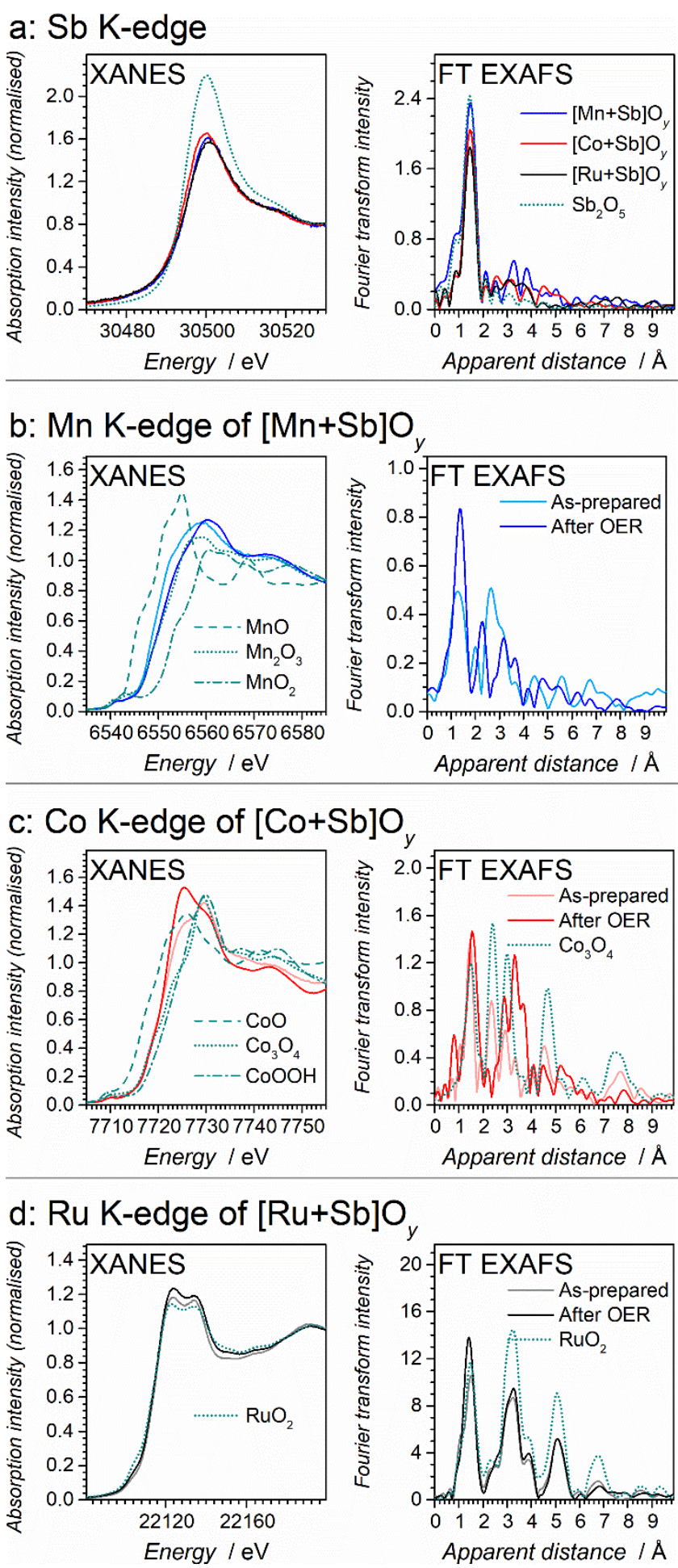

Figure 2. XAS data at (a) $\mathrm{Sb}$, (b) $\mathrm{Mn}$, (c) $\mathrm{Co}$ and (d) Ru K-edges obtained for $[\mathrm{Mn}+\mathrm{Sb}] \mathrm{O}_{y}($ blue $),[\mathrm{Co}+\mathrm{Sb}] \mathrm{O}_{y}(\mathrm{red})$ and $[\mathrm{Ru}+\mathrm{Sb}] \mathrm{O}_{y}$ ( black) before ( pale solid traces) and after ( vivid solid traces) electrocatalytic tests in stirred $0.5 \mathrm{M} \mathrm{H}_{2} \mathrm{SO}_{4}$ compared to the defined reference materials ( dashed and dotted teal traces). (e-h) Fourier Transform of EXAFS at (e) $\mathrm{Sb}$, (f) $M \mathrm{n}$, (g) $\mathrm{Co}$ and (h) Ru K-edges. [ $\mathrm{Mn}+\mathrm{Sb}] \mathrm{O}$ y and [Co+Sb] 0 were tested for $24 \mathrm{~h}$ at $10 \mathrm{~mA} \mathrm{~cm}^{-2}$ and then for $1 \mathrm{~h}$ at 2.03 and $1.93 \mathrm{~V}$ vs. RHE at ambient temperature; $[\mathrm{Ru}+\mathrm{Sb}] \mathrm{O}_{y}$ was tested for $12 \mathrm{~h}$ at $10 \mathrm{~mA} \mathrm{~cm}^{-2}$ at $80^{\circ} \mathrm{C}$.

As expected from XRD (Figure $3 \mathrm{a}$ ), $\mathrm{M} \mathrm{nSb_{2 } \mathrm { O } _ { 6 }}$ alone could not de-

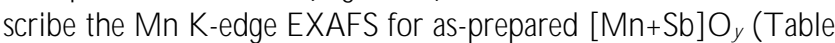
S2) due to the presence of a manganese oxide compound, most likely $\mathrm{M} \mathrm{n}_{2} \mathrm{O}_{3}$, which produces a peak at $c a 2.5-2.6 \AA$ in FT EXAFS ( Figures $2 b$ and S21f). After the $O E R$, the intensity of the $\mathrm{M} \mathrm{n}_{2} \mathrm{O}_{3}$ features in EXAFS are suppressed ( Figures $2 b$ and $S 21 c$, T able S2), which indicates partial loss of $\mathrm{M} \mathrm{n}_{2} \mathrm{O}_{3}$ and corroborates the corrosion data ( $T$ able 1). Given that this loss does not induce any notable deterioration in the catalytic activity ( Figure $1 \mathrm{~b}$ ), we conclude that individual $\mathrm{Mn}$ oxides do not make a significant contribution to the $O E R$ performance of $[\mathrm{Mn}+\mathrm{Sb}] \mathrm{O}$.

XAS data recorded at the $\mathrm{Co} \mathrm{K}$-edge for [ $\mathrm{Co}+\mathrm{Sb}] \mathrm{O}_{y}$ confirmed the $X R D$ observations of the presence of $\mathrm{C}_{3} \mathrm{O}_{4}$ in the as-prepared material, which vanished after the $0 \mathrm{ER}$ tests ( Figure $2 \mathrm{c}$ and $\mathrm{S} 22 \mathrm{c}, \mathrm{e}$ ). The XAS data of the tested catalyst are well fit with the simulations based on the $\mathrm{C}_{0} \mathrm{Sb}_{2} \mathrm{O}_{6}$ structure ${ }^{67}$ (Figure S22c, f and T able S3). O n this basis, we interpret the initial rapid drop in the performance of $\left[\mathrm{Co}+\mathrm{Sb} \mathrm{O}_{y}\right.$ (Figure $\mathrm{Ib}$ ) by the dissolution of the catalytically more active $\mathrm{C}_{3} \mathrm{O}_{4}$ phase from the material surface, while the quasi-stabilised performance achieved after $c a 20 \mathrm{~h}$ is ascribed to the true cataIytic activity of cobalt antimonate.

The most challenging to interpret set of physical characterisation data among examined systems was obtained for the top-performing [Ru+Sb] 0 y catalyst. Analysis of the Ru $3 d$ XP spectra is complicated by a direct overlap with $C$ 1s signals, but it was still possible to conclude that the initial mixed $\mathrm{Ru}^{3+}+\mathrm{Ru}^{4+}$ state of the surface undergoes oxidation during the $O E R$ to become dominated by $\mathrm{Ru}^{4+}$ (Figure S17c and S18c) ${ }^{68}$ In turn, Ru K -edgeXAN ES recorded for fresh and tested $[\mathrm{Ru}+\mathrm{Sb}] \mathrm{O}_{y}$ were in a perfect agreement with the $\mathrm{Ru} \mathrm{u}^{4+}$ state, closely resembling the spectra of $\mathrm{RuO}_{2}$ ( Figure $2 \mathrm{~d}$ ).

Interpretation of the XRD data for $[\mathrm{Ru}+\mathrm{Sb}] \mathrm{O}_{y}$ was not straightforward as the diffraction pattern of rutile $\mathrm{RuO}_{2}$ is similar to that of the anticipated trirutile antimonate phase. $N$ evertheless, the major set of broad diffraction peaks at $28,35,40,54$ and $69.5^{\circ}$ matches well the positions and relative intensities of the tabulated pattern of ruthenium (IV) oxide ( grey bars in Figure 3c). This interpretation suggests that the $\mathrm{Sb}$ component(s) give rise to a set of broad low-intensity signals at $c a 25,30.5$ and $48^{\circ}$ that can be attributed to highly disordered $\mathrm{Sb}_{2} \mathrm{O}_{5}$, along with two peaks at $\mathrm{ca} 38.5$ and $44^{\circ}$ (marked with triangles Figure $3 \mathrm{c}$ ). 0 ne might suggest that these two reflections can be attributed to an antimonate phase which other diffraction peaks are presumably merged with the signals of $\mathrm{RuO}_{2}$. H owever, analysis of the highly resolved up to $R^{\prime}=8 \AA$ Ru K-edge EXAFS collected for [Ru+Sb] ${ }_{y}$ does not support this hypothesis (Figures $2 \mathrm{~d}$ and S24). Fitting of these data with simulations based on a RuSb ${ }_{2} \mathrm{O}_{6}$ type lattice did not produce any satisfactory level of agreement ( Figure S24 and T able S4). C learly resolved FT EXAFS peaks at high $R$, of $3.1,3.9,5.1,6.8 \AA$ present in the catalyst before and after the $O E R$ tests are associated with groups of Ru-Ru distances at 5.0, 6.8 and 7.2 $\AA$, and cannot be explained by the $\mathrm{RuSb}_{2} \mathrm{O}_{6}$ phase. In fact, the EXAFS and XANES of [Ru+Sb] $0_{y}$ are almost perfectly consistent with the $\mathrm{RuO}_{2}$ structure, although with a slightly increased level of disorder (Figures $2 d$ and S24, T able S4), which corroborates the major XRD signals (Figure $3 \mathrm{c}$ ).

T aken together, $X A S$ and XRD suggest that the ruthenium structure in [ $\mathrm{Ru}+\mathrm{Sb}] \mathrm{O}_{y}$ is very close to the $\mathrm{RuO}_{2}$ lattice, which opens a question on the origin of the significantly improved electrocatalytic performance of the mixed oxide system as opposed to $\mathrm{RuO}_{2}$ (Figure 1 and S4a). To shed light on this, detailed TEM investigations with elemental mapping were undertaken. 


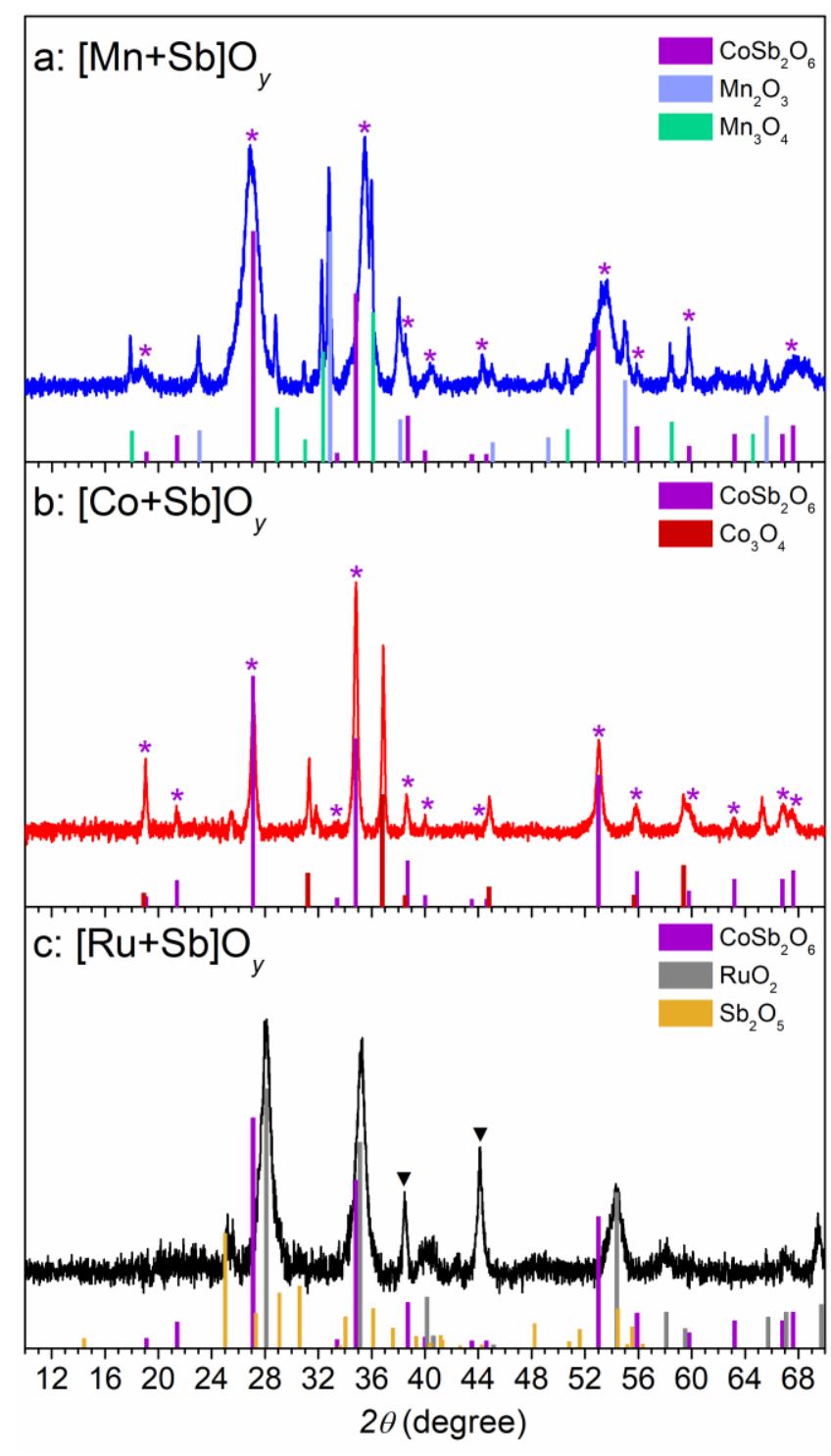

Figure 3. X-ray diffractograms of as-synthesised (a) $[\mathrm{Mn}+\mathrm{Sb}] \mathrm{O}_{y_{1}}$ (b) $[\mathrm{Co}+\mathrm{Sb}] \mathrm{O}_{y}$ and $(\mathrm{c})[\mathrm{Ru}+\mathrm{Sb}] \mathrm{O}_{y}$. Vertical lines show tabulated positions and relative intensities for $(\mathrm{a}-\mathrm{c}) \mathrm{CoSb}_{2} \mathrm{O}_{6}$ ICSD-108964, (a) $\mathrm{Mn}_{2} \mathrm{O}_{3}$ ICDD-00-041-1442 and $\mathrm{Mn}_{3} \mathrm{O}_{4}$ ICDD-01-075-1560, (b), $\mathrm{CO}_{3} \mathrm{O}_{4}$ ICSD-36256, (c) RuO 2 ICSD-731469 and $\mathrm{Sb}_{2} \mathrm{O}_{5}$ PDF-01-0710256. M ean crystallite sizes calculated using Scherrer equation were: (a) $d_{X R D}\left(\mathrm{MnSb}_{2} \mathrm{O}_{6}\right) \approx 7 \mathrm{~nm}, d_{\mathrm{XRD}}\left(\mathrm{Mn}_{2} \mathrm{O}_{3}\right) \approx 35 \mathrm{~nm}, \mathrm{dxRD}_{\mathrm{RD}}\left(\mathrm{Mn}_{3} \mathrm{O}_{4}\right) \approx 41$ $\mathrm{nm} ;$ (b) $d_{X R D}\left(\mathrm{COSb}_{2} \mathrm{O}_{6}\right) \approx 24 \mathrm{~nm} ; d_{\times R D}\left(\mathrm{CO}_{3} \mathrm{O}_{4}\right) \approx 43 \mathrm{~nm}$; (c) $d_{X R D}\left(\mathrm{RuO}_{2}\right) \approx 10 \mathrm{~nm}$. Asterisks indicate diffraction peaks attributed to the antimonate phase. T riangles indicate peaks which assignment is not straightforward.

At low to moderate magnification, STEM-EDS analysis of [Ru+Sb]O y showed ruthenium and antimony to be intimately mixed, both before and after the O ER tests ( Figures 4a-b and S25). Conventional TEM imaging demonstrated that the catalyst represents a very fine assembly of nanocrystals, typically less than $10 \mathrm{~nm}$ in size, embedded into another material that appears significantly more structurally disordered (Figures 4c-d and S26) . H igher magnification images revealed clear lattice fringes of ca $3 \AA$ for the crystalline nanoparticles, which can be attributed to $\mathrm{RuO}_{2}$ with a relatively high degree of crystalline order ( Figure 4c-d).
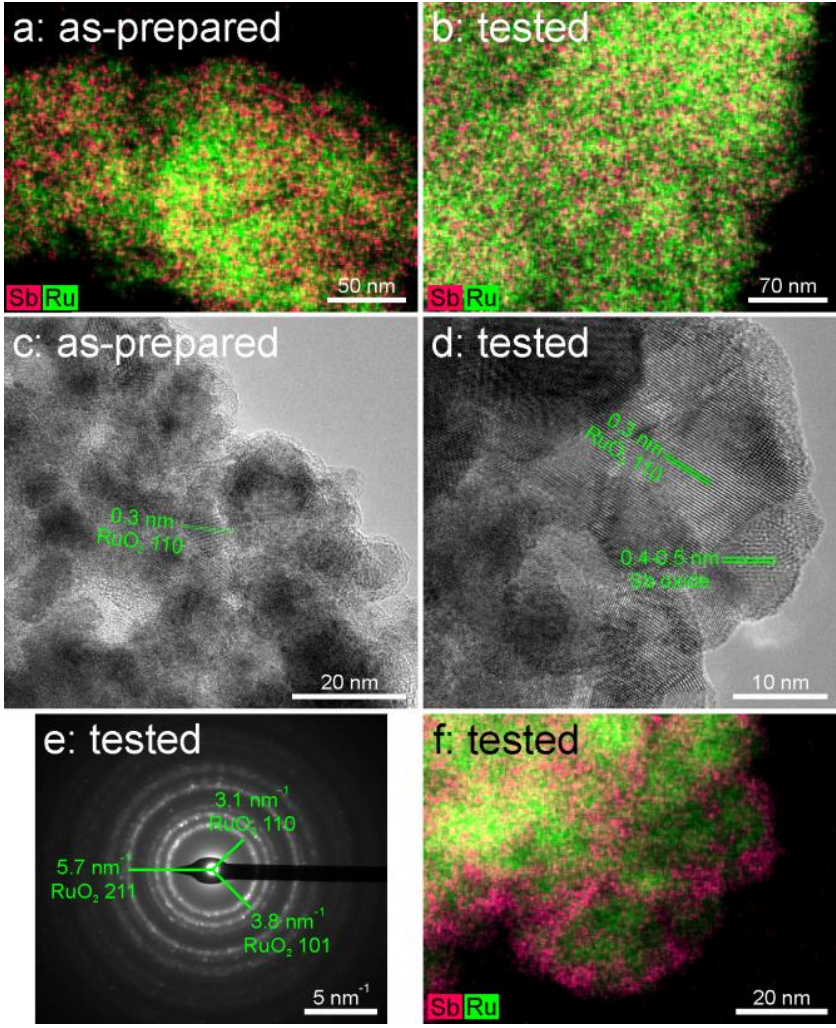

Figure 4. TEM and STEM-EDS characterisation of [Ru+Sb] ${ }_{y}$ before and after OER tests in stirred $0.5 \mathrm{M} \mathrm{H}_{2} \mathrm{SO}_{4}$ at $10 \mathrm{~mA} \mathrm{~cm}^{-2}$ for $24 \mathrm{~h}$ at $80^{\circ} \mathrm{C}$ : (a-b) medium magnification STEM -EDS mapping of the (a) asprepared and (b) tested catalyst; (c-d) TEM micrographs of the (c) asprepared and (d) tested catalyst; (e) selected area electron diffraction taken from a region containing large amounts of both $\mathrm{Ru}$ and $\mathrm{Sb}$ for the tested catalyst. (f) ST EM -EDS mapping analysis of the extended area of the tested catalyst around the region shown in panel $d$.

This is also illustrated in the selected area electron diffraction pattern, which can beindexed as essentially pure $\mathrm{RuO}_{2}$ ( Figure 4e) notwithstanding it was recorded from a large fragment containing both ruthenium and antimony. The material closely neighbouring $\mathrm{RuO}_{2}$ nanocrystals exhibited larger lattice fringes of ca 4-5 $\AA$ ( Figure $4 d$ ), which cannot be ascribed to ruthenium oxide and therefore are attributed to antimony oxides. ST EM -ED S mapping of this area confirmed the partial segregation of ruthenium and antimony at the nanoscale (Figure 4f), but we emphasise that the two elements were still found to be mixed very finely, even when analysed at up to $1.3 \mathrm{M} \times$ magnification (Figures $4 \mathrm{f}$ and S27).

0 ther antimony rich areas were generally devoid of clear lattice fringes ( Figure 4c-d), and although this does not definitely rule out crystallinity, it tends to support a hypothesis that $\mathrm{Sb}$ oxides in [Ru+Sb] $0_{y}$ exhibit a very high level of disorder. We also note that the Sb phase appears to coat the edges and interstices of the $\mathrm{RuO}_{2}$ nanocrystals in the catalysts after the OER test ( Figure 4f), suggesting that antimony has been lost from a previously predominating Sbbased coating of Ru oxide particles rather than a simple aggregation of two phases. This supports the corrosion data ( $T$ able 1).

0 verall, the physical characterisation data reveal several fundamental differences in the investigated catalysts. As-prepared [M n+Sb] ${ }_{y}$ and $[\mathrm{Co}+\mathrm{Sb}] \mathrm{O}_{y}$ contain a mixture of individual metal oxides, which majorly dissolve during the $\mathrm{OER}$ tests, with a metal antimonate oxide phase. Thelatter ismost likely $\mathrm{CoSb}_{2} \mathrm{O}_{6}$ in $[\mathrm{Co}+\mathrm{Sb}] \mathrm{O}_{y}$, whilethe 
structure of the manganese-antimony oxide exhibits some distinctions from the published features of the antimonate phase and a significant level of disorder. At the same time, no evidence for the formation of a ruthenium antimonate was obtained. Instead, the [Ru+Sb] $O_{y}$ catalyst contains highly-dispersed $\mathrm{RuO}_{2}$ crystallites embedded into and decorated with disordered antimony oxides. O ne might hypothesise that an interaction and intermixing between ruthenium and antimony oxides might still occur, but at the topmost surface layers of $\mathrm{RuO}_{2}$, especially at the abundant intergrain boundaries visualised by TEM ( Figure 4c-d), rather than in the bulk phase. To assess this possibility and further assist in establishing a plausible explanation of the improved electrocatalytic performance of [Ru+Sb] $\mathrm{y}_{y}$, theoretical analysis of the metal-antimonate systems was undertaken.

\section{Theoretical insights into the improved stability of the Co- $\mathrm{Sb}$ and $\mathrm{Ru}-\mathrm{Sb}$ oxides}

Experimental evidence on the stabilisation against corrosion of the oxides of transition metals like $\mathrm{Co}, \mathrm{Mn}, \mathrm{Ni}$ and $\mathrm{Ru}$, through their combination with the oxides that are thermodynamically stable under the OER conditions exists, ${ }^{12,31-44}$ including the new results reported in the present work. H owever, there is a lack of the understanding behind this stabilising effect, which we aimed to address through the theoretical analysis of two systems of interest herein $\mathrm{Co}-\mathrm{Sb}$ and $\mathrm{Ru}$-Sb mixed oxides. Extending the analysis to the $\mathrm{M} \mathrm{n}-\mathrm{Sb}$ combination could not be realised due to a well-documented complex ground state magnetic structure of $\mathrm{M} \mathrm{n}_{2} \mathrm{O}_{3}$, which exhibits noncollinear magnetic ordering and introduces significant uncertainties to the modelling of the electronic structure. ${ }^{69-70}$

Assessment of the electrochemical and structural stability was undertaken through the computation of cohesive energies of the materials of interest and also differences in the dissolution potentials $\left(\Delta E_{\mathrm{d}}\right)^{71-73}$ for the Ru-Sb system. Both approaches have been previously validated through comparisons of the theoretical predictions and experimental electrochemical stability data for a range of systems, in particular metal oxides. ${ }^{74-76}$

For the $\mathrm{C}$-Sb combination, the simulated compositional phase diagram ( Figure 5a) indicates a broad chemical potentials space that favours the formation of $\mathrm{C}_{\mathrm{Sb}_{2} \mathrm{O}_{6}}$ (structure shown in Figure S28) as opposed to individual oxides. Experimental data suggest that this phase dominates the $[\mathrm{Co}+\mathrm{Sb}] \mathrm{O}_{y}$ catalyst under the $\mathrm{OER}$ conditions and was therefore used for further theoretical analysis. As a point of reference in the calculations, $\mathrm{CO}_{3} \mathrm{O}_{4}$ - the dominating phase of the $\mathrm{CoO}_{x}$ control - was considered. Cohesive energies for $\mathrm{CO}_{3} \mathrm{O}_{4}$ and $\mathrm{CoSb}_{2} \mathrm{O}_{6}$ were simulated as $-12.8 \mathrm{eV}$ and $-15.4 \mathrm{eV}$ per formula unit, respectively, which indicates improved overall structural and electrochemical stability ${ }^{77}$ of the antimonate as compared to the monometallic oxide. The improvement in cohesive energies is likely to be partially associated with the higher bond energy for Sb-0 (434 kJ $\mathrm{mol}^{-1}$ ) as compared to $\mathrm{Co-O}\left(397 \mathrm{~kJ} \mathrm{~mol}^{-1}\right){ }^{78}$ although one might note that this difference does not appear sufficient to explain the calculated cohesive energies. Therefore, we hypothesised if the presence of $\mathrm{Sb}$ in the structure might strengthen the $\mathrm{C} 0-\mathrm{O}$ bond through changes in the electronic structure.

The above supposition was assessed through the analysis of the atom/ orbital projected partial density of states (PDOS), calculated bond lengths and Bader charges. The PDOS for $\mathrm{CO}_{3} \mathrm{O}_{4}$ demonstrates a reasonable hybridisation of the oxygen $\mathrm{p}$-orbitals with $\mathrm{d}$-orbitals of cobalt in tetrahedral sites but not in octahedral ones; this is in contrast to $\mathrm{CoSb}_{2} \mathrm{O}_{6}$ where only one type of $\mathrm{Co}$ sites is present and is strongly hybridised with $02 p$ ( FigureS29a-b). It is also noted that the latter interact much stronger with $\mathrm{Co} 3 \mathrm{~d}$ orbitals rather than with Sb $5 p$.

\section{a: Co-Sb-O phase diagram}
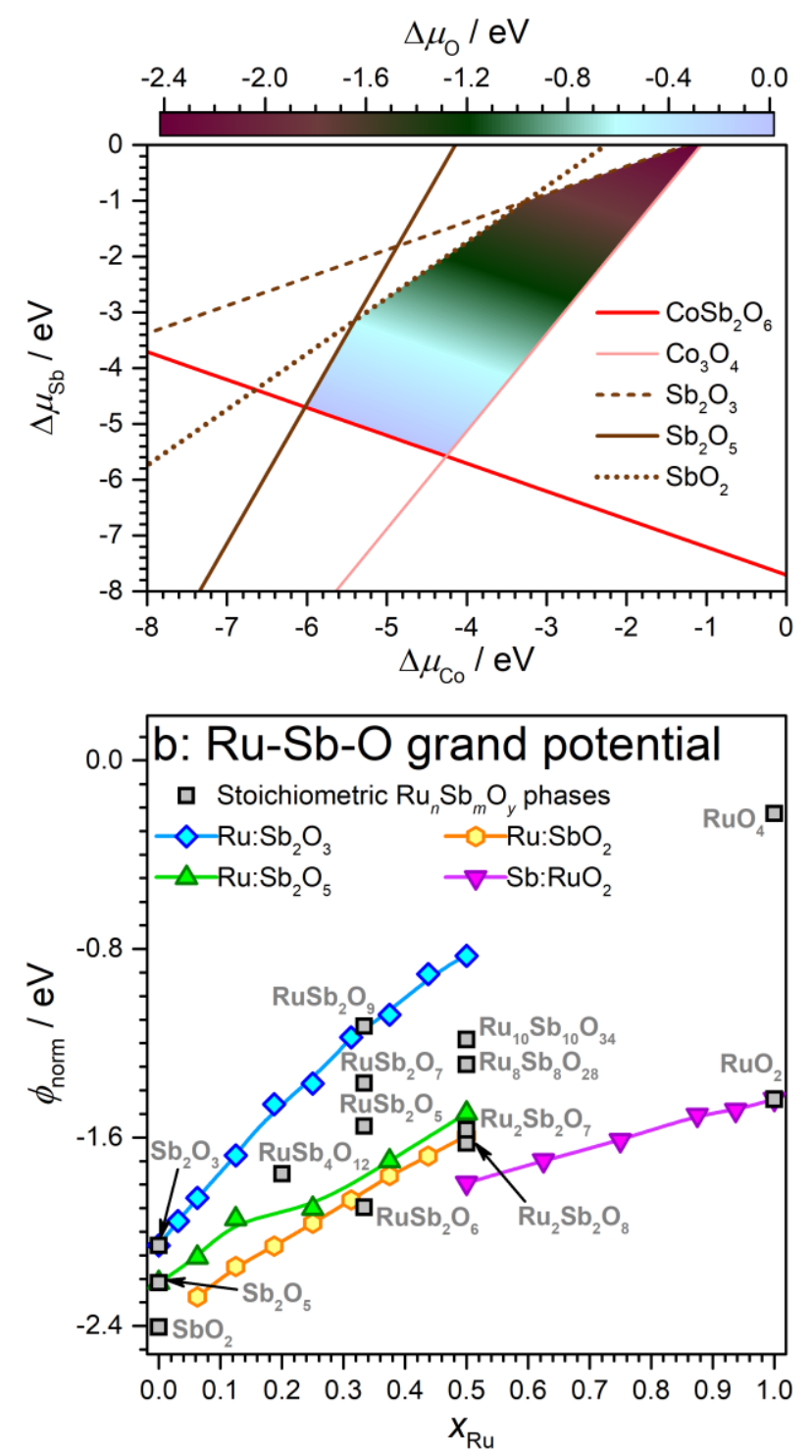

Figure 5. (a) Simulated compositional phase diagram of $\mathrm{CoSb}_{2} \mathrm{O}_{6}$ against individual oxides. Shaded area corresponds to the stable region of $\mathrm{CoSb}_{2} \mathrm{O}_{6}$, where the colour scale shows the allowed chemical potentials for oxygen; coloured lines and the corresponding spaces opposite to the shaded region present the stable regions of the identified individual oxides. (b) N ormalised oxygen grand potential ( $\phi_{\text {norm }}$ ) vs. ruthenium atomic fraction, $x_{R u}=n /(n+m)$, calculated for $\left[R_{n}+S b_{m}\right] O_{y}$ at $T=600{ }^{\circ} \mathrm{C}$ and 0.21 atm $\mathrm{O}_{2}$ partial pressure. $\mathrm{Sb}: \mathrm{RuO}_{2}-\mathrm{Sb}$-doped $\mathrm{RuO}_{2} ; \mathrm{Ru}: \mathrm{SbO}_{2}, \mathrm{Ru}: \mathrm{Sb}_{2} \mathrm{O}_{3}$ and $\mathrm{Ru}: \mathrm{Sb}_{2} \mathrm{O}_{5}-\mathrm{Ru}$-doped antimony oxides. Calculated data are shown as symbols; lines are guides to an eye.

Since the electrocorrosion of materials is an interfacial phenomenon, the above findings were al so corroborated by the analysis of the characteristic catalyst surfaces - (110) oriented facet for $\mathrm{CoSb}_{2} \mathrm{O}_{6}$ and (110)-A terminated surface for $\mathrm{C}_{3} \mathrm{O}_{4}{ }^{79-81}$ (Figure S28c-d). Comparisons of the PD OS of bulk and (110) surfaces suggest that the slab geometry produces surface states just above the valence band due to the undercoordinated $\mathrm{CO}^{3+}, \mathrm{CO}^{2+}$ and $\mathrm{O}^{2-}$ ions, which 
renders these surfaces metallic. Similar to the bulk, $2 p$ orbitals of the surface $\mathrm{O}$ in $\mathrm{COSb}_{2} \mathrm{O}_{6}$ interact stronger with $\mathrm{Co}_{0} \mathrm{~d}$ as compared to $\mathrm{Sb} 5 \mathrm{p}$ orbitals. Enhanced $\mathrm{O}-\mathrm{p}-\mathrm{Co}$-d interaction in $\mathrm{CoSb}_{2} \mathrm{O}_{6}$ is additionally verified by the calculated PDOS of sub d-orbitals of $\mathrm{CO}^{2+}$ in $\mathrm{CO}_{3} \mathrm{O}_{4}$ and $\mathrm{COSb}_{2} \mathrm{O}_{6}$ (Figure $\mathrm{S} 30$ ).

The features of the PDOS discussed above can be expected to make the overall cohesive energy of $\mathrm{CoSb}_{2} \mathrm{O}_{6}$ more negative than that of $\mathrm{C}_{3} \mathrm{O}_{4}$ and hence enhance the driving force required for the electrocorrosion of cobalt. Furthermore, the simulated $\mathrm{CO}-\mathrm{O}$ and $\mathrm{Sb}-\mathrm{O}$ bond lengths in $\mathrm{CoSb}_{2} \mathrm{O}_{6}$ were lower and higher than the corresponding expected values based on the combined ionic radii, respectively ( $2.08 \AA$ calculated vs. $2.105 \AA$ expected for high spin C 0-0 ; $2.02 \AA$ calculated vs. $1.98 \AA$ expected for Sb-0). T his internal compressive strain of the $\mathrm{C} 0-\mathrm{O}$ bonds can be associated with the higher electronegativity of $\mathrm{Sb}$ as compared to $\mathrm{C} 0$. C alculated Bader charges on $\mathrm{C} \mathrm{O}^{2+}$ in $\mathrm{C}_{3} \mathrm{O}_{4}$ and $\mathrm{CoSb}_{2} \mathrm{O}_{6}$ were $+1.31 e$ and +1.36 e, respectively, which further supports the stronger $\mathrm{Co}-\mathrm{O}$ bond in the antimonate as compared to the individual metal oxide.

$\mathrm{N}$ ext, the ruthenium-antimony system was analysed following a similar approach. As discussed above, no robust experimental evidence for the formation of a stabile ruthenium-antimony oxide phase was obtained. In line with these experimental observations, total energies calculated by DFT simulations indicated that hypothesised $\mathrm{RuSb}_{2} \mathrm{O}_{6}$ phase is unstable with respect to the individual oxides ( $T$ able S5). This prompted us to undertake a simulation of a grand potential phase diagram of the Ru-Sb system (Figure $5 b$ ), which enables prediction of the thermodynamically stable compositions that can be formed under relevant synthesis conditions, ${ }^{82}$ i.e. at $T=600^{\circ} \mathrm{C}$ and $0.2 \mathrm{~atm} \mathrm{O}_{2}$ partial pressure in the present work.

0 xygen grand potentials were calculated for various $\left[\mathrm{Ru}_{n}+\mathrm{Sb}_{m}\right] \mathrm{O}_{\text {y }}$ structures and compositions as a function of the metal atomic fraction, $X_{R u}=n /(n+m)$. In addition to a broad range of stoichiometric compounds, substitutional doping of Sb into $\mathrm{RuO}_{2}\left(\mathrm{Sb}: \mathrm{RuO}_{2}\right)$ and $\mathrm{Ru}$ in antimony oxides was considered. Among these different possibilities, the lowest $\phi_{\text {norm }}$ at $x_{R u}=0.5$, i.e. the highest stability under the conditions employed during the synthesis of [Ru+Sb] $0_{y}$, was calculated for the ruthenium(IV) oxide doped with antimony. In fact, $\mathrm{Sb}: \mathrm{RuO}_{2}$ are theoretically predicted to be more stable than the parent metal oxide within the $x_{R u}$ range examined (Figure $5 \mathrm{~b}$ ). At the same time, the experimental XAS data provide a compelling evidence for the dominant state of ruthenium in [ $\mathrm{Ru}+\mathrm{Sb}] \mathrm{O}_{y}$ being very similar to that in $\mathrm{RuO}_{2}$ ( vide supra). On this basis, further analysis focused on $\mathrm{RuO}_{2}$ at low levels of Sb doping.

Differences in the electronic properties of the $\mathrm{RuO}_{2}$ reference and $\mathrm{Sb}: \mathrm{RuO}_{2}$ were investigated based on the computations with a $2 \times 2 \times 2$ supercell of tetragonal 6-atom $\mathrm{RuO}_{2}$ unit cell containing $16 \mathrm{Ru}$ and 320 atoms. First, through the examination of the calculated spin polarised total density of states, we note that Sb substitution into $\mathrm{RuO}_{2}$ maintains its metallic character and even further improves the electrical conductivity as concluded from the shift of the conduction band (Figure S31), which is a positive finding from the perspective of the electrocatalytic activity. Further, and most importantly, improved stability of $\mathrm{Ru}^{4+}$ within the $\mathrm{Sb}: \mathrm{RuO}_{2}$ materials was confirmed by the positive difference in the dissolution potential ${ }^{71-73} \Delta E_{\mathrm{d}}=$ $0.08 \mathrm{~V}$ and by the negative increase in the cohesive energies when compared to undoped $\mathrm{RuO}_{2}$. Specifically, the cohesive energy changesfrom -3.28 $\left(\mathrm{RuO}_{2}\right)$ to $-3.51\left(\mathrm{Sb}_{0.0625}: \mathrm{Ru}_{0.9375} \mathrm{O}_{2}\right)$ and $-3.62 \mathrm{eV}$ per unit formula $\left(\mathrm{Ru}_{0.813} \mathrm{Sb}_{0.187} \mathrm{O}_{2}\right)$. T his favourable change is again explained by the enhanced strength of the Ru-O bond, which is indicated by the stronger overlap of $02 p$ and $R u 3 d$ orbitals in the PDOS (Figure S32) as well as by the higher Bader charge on ruthenium in $\mathrm{Sb}_{0.0625}: \mathrm{Ru}_{0.9375} \mathrm{O}_{2}(+1.76 \mathrm{e})$ as compared to $\mathrm{RuO}_{2}(+1.70 \mathrm{e})$. Enhanced charge donation from ruthenium to neighbouring oxygen atoms is also supported by the differences in the partial density of states of Ru $4 d$ sub-orbitals (Figure S33).

In summary, the computational analysis suggests that the improvement in the stability of Ru and $\mathrm{Co}$ oxides upon combination with $\mathrm{Sb}$ oxide is majorly stemming from the electronic effects of antimony that strengthen the metal-oxygen bonds. Aggregate of the experimental and computational data for the Ru-Sb system suggests that, although the well-defined ruthenium antimonate phase is unlikely to be formed, doping of ruthenium( IV) oxide with antimony is possible. Taking into account the experimental data indicating the formation of the slightly distorted $\mathrm{RuO}_{2}$ phase (Figures $2 \mathrm{~d}, 3 \mathrm{c}$ and 4 ) and the very significant level of corrosion of antimony but not of ruthenium during the OER tests of [Ru+Sb] $0_{y}$ (Tables 1 and 2), we hypothesise that $\mathrm{Sb}$ doping might be majorly confined to the surface of the $\mathrm{RuO}_{2}$ crystallites. The formation of this protective layer is likely to be sufficient to provide the enhanced stability of the material against the electrocorrosion highlighted above ( Figure 1) and as even more strongly emphasised through the durability tests at elevated temperature that are discussed below.

\section{Longer-term operation at elevated temperature}

A final set of tests was undertaken to assess the ability of the two most promising catalysts investigated herein, viz. [M $\mathrm{M}+\mathrm{Sb}] \mathrm{O}_{y}$ and [Ru+Sb] $0_{y}$, to operate for extended periods of time and at elevated temperatures. Voltammetric analysis confirmed the expected positive effect of increasing the temperature on the kinetics of the $O E R$ catalysed by both $\mathrm{Mn}$ - and Ru-based materials (Figure 6a-b). The apparent activation energy of the $O E R$ at an $I R$-corrected overpotential of $0.6 \mathrm{~V}$ approximated from the backward potentiodynamic scans for [ $\mathrm{M} \mathrm{n}+\mathrm{Sb}] \mathrm{O}$ y is ca20 $\pm 10 \mathrm{~kJ} \mathrm{~mol}^{-1}$ (Figure S35). This is notably lower than values reported for other $0 \mathrm{ER}$ catalysts operating at low $\mathrm{pH},{ }^{83-84}$ and probably reflects the increasing instability of this material at elevated temperatures as discussed below.

While no significant deterioration of the $[\mathrm{Mn}+\mathrm{Sb}] \mathrm{O}_{y}$ performance was observed in the voltammetric regime ( Figure S36a), short-term $24 \mathrm{~h}$ galvanostatic tests revealed that this catalyst suffers detectable losses in activity at $60^{\circ} \mathrm{C}$ ( F igure S36b-C). D uring these experiments, the overpotential required to maintain the $O E R$ rate of $10 \mathrm{~mA} \mathrm{~cm}$ increased almost linearly, meaning an exponential decrease in the activity of the catalyst, at an average rate of $c a 0.001-0.002 \mathrm{~V} \mathrm{~h}^{-1}$. When longer-term testing was undertaken at $80{ }^{\circ} \mathrm{C}$, degradation at essentially the same rate was observed over the initial ca $100 \mathrm{~h}$ of measurements (Figure 6b). Afterwards, an abrupt loss of the performance, reflected by an increase of the potential to ca2.1 V vs. RH E occurred, which was then maintained for at least another $24 \mathrm{~h}$. The latter observation suggests that the change in the OER activity observed in these experiments is unlikely to be associated with the degradation of the FTO support, which would result in a complete loss of any ability of the electrode to sustain water electrooxidation due to the disruption of the electrical contact. $0 \mathrm{n}$ the basis of these new data ( Figures $1 \mathrm{~b}$ and $6 \mathrm{~b}$; Figure S36b), we conclude that manganese antimonate is a promising non-noble-metal-based water oxidation catalyst capable of a reasonably stable operation in acidic electrolyte solutions, but it is unlikely to be suitable for applications at $60^{\circ} \mathrm{C}$ and higher temperatures. 

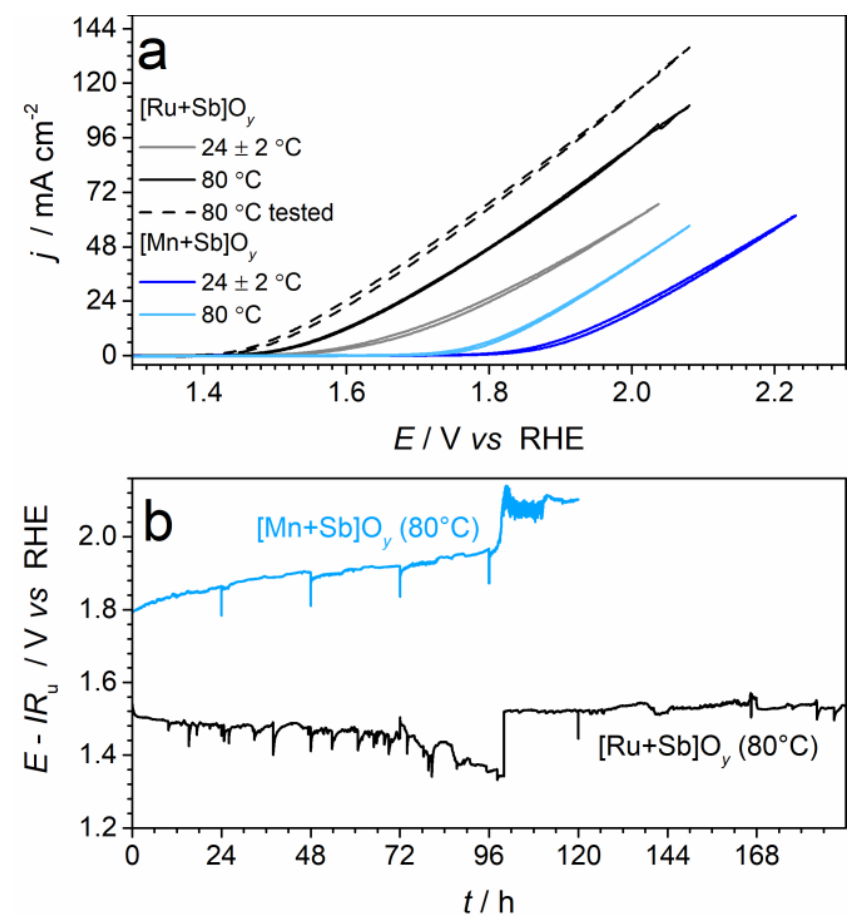

Figure 6. Performance of the $[\mathrm{Ru}+\mathrm{Sb}] \mathrm{O}_{y}\left(\right.$ black) and $[\mathrm{Mn}+\mathrm{Sb}] \mathrm{O}_{y}$ (blue) catalysts during the $0 \mathrm{ER}$ in stirred $0.5 \mathrm{M} \mathrm{H}_{2} \mathrm{SO}_{4}$ at $80{ }^{\circ} \mathrm{C}$ : (a) cyclic voltammetry (scan rate $0.02 \mathrm{~V} \mathrm{~s}^{-1}$; not $/ R_{\mathrm{u}}$-corrected; third scans) before ( vivid traces) and after ( pale traces) long-term tests shown in panel b (dashed curves show data collected at $24 \pm 2{ }^{\circ} \mathrm{C}$ ), and (b) $/ R_{u^{-}}$ corrected chronopotentiograms ( $10 \mathrm{~mA} \mathrm{~cm}^{-2}$ geom.).

The behaviour of $[\mathrm{Ru}+\mathrm{Sb}] \mathrm{O}_{y}$ at $80^{\circ} \mathrm{C}$ was remarkably different to that of $[\mathrm{Mn+Sb}] \mathrm{O}_{y}$ (Figures $6 \mathrm{a}$ and S37). First, the rutheniumbased catalyst demonstrated a robust operation for $192 \mathrm{~h}$ of chronopotentiometry at $10 \mathrm{~mA} \mathrm{~cm}^{-2}$ and additional $1 \mathrm{~h}$ of chronoamperometry at 2.03 and $1.93 \mathrm{~V}$ vs. RHE (Figure $6 \mathrm{~b}$ and S37b-c). A part from the self-healing $\mathrm{Co}$-Fe-Pb system ${ }_{1}^{38}$ we are not aware of any other recently reported $O E R$ electrocatalyst capable of similarly stable operation under such comparably harsh conditions. Second, comparisons of the cyclic voltammetric data recorded before and after long-term tests reveal a notable improvement in the performance of the catalyst. This positive change was also observed in short-term ambient temperature tests (Figure 1a) and is likely to be associated with a significant increase of the amount of ruthenium on the surface due to the loss of the catalytically inactive $\mathrm{SbO}{ }_{x}(\mathrm{~T}$ able 2$)$ but not $\mathrm{Ru}$ (T able 1). The stabilised catalytic activity for the OER of an essentially flat $\left[\mathrm{Ru}+\mathrm{SbO}_{y}\right.$ ] electrode at $80^{\circ} \mathrm{C}$ and $\mathrm{pH} 0.3$ corresponds to the reaction rate of $10 \mathrm{~mA} \mathrm{~cm}^{-2}$ geom. at an IR-corrected overpotential of $0.33-0.35 \mathrm{~V}$ (1.51-1.53 V vs. RHE).

\section{CONCLUSIONS}

The combination of transition metal and antimony oxides in a pursuit of the creation of robust and active catalysts for the electrooxidation of water under acidic conditions was found to produce very different outcomes depending on the chemical nature of the metal employed. While nickel and iron did not yield efficient catalytic systems, mixing $\mathrm{Sb}$ with cobalt, manganese and ruthenium resulted in materials with quite distinct structural features, but all demonstrating one very significant and critically important advantage with respect to the individual metal oxides - significantly improved operational stability. The origin of this positive effect can now be explained by the antimony-induced increase in the metal- oxygen bond strength, which substantially suppresses the electrooxidative dissolution, as revealed through the computational studies. The theoretical treatment implemented herein might be considered for future high-through put screening studies for the identification of robust electrocatalysts for the $0 E R$.

Another set of key findings of the present work stems from the exhaustive durability tests of the materials at different temperatures. While demonstration of apparently stable operation of the oxygen evolution reaction catalysts at low $\mathrm{pH}$ and ambient temperature on a short timescale does not present a very significant research challenge anymore, longer term operation at elevated temperatures of practical interest is still hard to achieve. H erein, the instability of the promising manganese-antimony oxide catalysts at $60-80{ }^{\circ} \mathrm{C}$ was revealed to indicate that this system needs to be further improved if it is intended to be designed for operation in PEM water electrolysers. Contrasting this behaviour, mixed ruthenium-antimony oxides were found to be stable in operation at $80^{\circ} \mathrm{C}$ for at least one week, accompanied by negligible loss of the catalytically active metal into the solution. The lack of any recent reports on a similar performance during the electrooxidation of acidic water under comparably harsh conditionsallows us to consider this result as outstanding and highly promising in the context of the development of the anode catalysts for PEM water electrolysers.

Finally, the aggregate of results presented herein suggests that there might be two different mechanisms for stabilising electrocatalytically active species like cobalt, manganese, or ruthenium oxides via the combination with an acid-stable "matrix" during water oxidation. Thefirst is the formation of metal-matrix compounds either through doping or viatransformation into new phases like antimonates. The second, less obvious and highlighted in detail herein for the ruthenium-antimony oxide system, is based on the intimate mixing of the discrete phases at the nanoscale. T his mechanism might form a basis for a new promising strategy towards the design of electrocatalytic systems that exhibit outstanding stability while maintaining the high activity of the individual metal oxide.

\section{ASSOCIATED CONTENT}

Supporting Information. Experimental section and extended experimental data.

\section{AUTHOR INFORMATION}

\section{Corresponding Authors}

Rosalie K. H ocking: rhocking@swin.edu.au

Aftab Alam: aftab@phy.iitb.ac.in

Aswani Yella: aswani.yella@iitb.ac.in

Alexandr N.Simonov: alexandr.simonov@monash.edu

\section{Author Contributions}

$\$$ These authors contributed equally.

SL designed and undertook experiments, analysed and interpreted data, and co-wrote the manuscript. M C designed and undertook experiments, analysed and interpreted data, and co-wrotethe manuscript. A Yadav undertook computational studies and co-wrote the manuscript. BK recorded, analysed and interpreted XAS data. JK undertook computational studies. TW collected and interpreted the TEM data. PC collected and analysed the XPS data. BJ assisted with the collection and interpretation of the XAS data. AT contributed to the data interpretation and manuscript preparation. DRM contributed to the data interpretation and manuscript preparation. RKH supervised and undertook XAS analysis, interpreted data and co-wrote the manuscript. AA designed and 
supervised computational studies. AY ella co-supervised the project and interpreted data. AN S devised and co-supervised the overall project, analysed and interpreted data, and co-wrote the manuscript.

All authors have given approval to the final version of the manuscript.

\section{Funding Sources}

This work was funded by the Australian Research Council (Centre of Excellence for Electromaterials Science CE 140100012; Future Fellowship to AN S; Laureate Fellowship to DRM ), the Australian Renewable Energy Agency ("Renewable Hydrogen for Export" project 2018/ RN D 008 AS008), M N RE Government of India ( N CPRE-Phase II, IIT Bombay to AA and AYella), Early Career Research Award, Science and Engineering Research Board, Government of India (ECR/2016/000550 to AYella), and IITB-M onash Academy (PhD scholarship to SL).

\section{ACKNOWLEDGMENTS}

Different parts of this work were undertaken at the XAS beamline of the Australian Synchrotron, M onash Centre for Electron M icroscopy ( partially funded through ARC LIEF project LE 110100223), M onash X-ray platform, Indian N ational Centre for Photovoltaic Research and Education (NCPRE), Sophisticated Analytical Instrument Facility (SAIF), Central Surface Analytical Facility of IIT Bombay, and spacetime2 cluster at IIT Bombay; the authors are highly grateful for being provided with access to these facilities and resources. The authors also sincerely thank Dr T. Gengenbach (CSIRO, Australia) for guidance in the interpretation of the XPS data and M r H. T akur (IIT Bombay) for assistance with the collection of some of the XRD data.

\section{REFERENCES}

(1) Reier, T.; N ong, H. N .; Teschner, D.; Schlögl, R.; Strasser, P., Electrocatalytic Oxygen Evolution Reaction in Acidic Environments Reaction Mechanisms and Catalysts. Adv. Energy Mater. 2017, 7 (1), 1601275. https:// doi.org/ 10.1002/ aenm.201601275.

(2) M acF arlane, D. R.; Choi, J.; Suryanto, B. H. R.; Jalili, R.; C hatti, M.; Azofra, L. M.; Simonov, A. N., Liquefied Sunshine: Transforming Renewables into Fertilizers and Energy C arriers with Electromaterials. $A d v$. $\begin{array}{llll}\text { Mater. } & 2019, & & \end{array} 204804$. https:// doi.org/ 10.1002/ adma.201904804.

(3) https:// www.hydrogenics.com/2019/02/25/ hydrogenics-todeliver-worlds-largest-hydrogen-electrolysis-plant.

(4) Ayers, K.; Danilovic, N .; O uimet, R.; Carmo, M.; Pivovar, B.; Bornstein, M., Perspectives on Low-T emperature Electrolysis and Potential for Renewable $\mathrm{H} y d r o g e n$ at Scale. Annual Review of Chemical and Biomolecular Engineering 2019, 10 (1), 219-239. https:// doi.org/ 10.1146/ annurev-chembioeng-060718-030241.

(5) Kibsgaard, J.; Chorkendorff, I., Considerations for the scaling-up of water splitting catalysts. Nature Energy 2019, 4 (6), 430-433. https:// doi.org/ 10.1038/ s41560-019-0407-1.

(6) Geiger, S.; Kasian, 0 .; Ledendecker, $M$.; Pizzutilo, E.; M ingers, A. M.; Fu, W. T.; Diaz-M orales, 0 .; Li, Z.; O ellers, T .; Fruchter, L.; Ludwig, A.; M ayrhofer, K.J. J.; Koper, M. T. M .; Cherevko, S., T he stability number as a metric for electrocatalyst stability benchmarking. Nature Catal. 2018, 1 (7), 508-515. https:// doi.org/ 10.1038/ s41929-018-0085-6.

(7) Kasian, 0 .; Grote, J. P.; G eiger, S.; Cherevko, S.; M ayrhofer, K.J. J., The Common Intermediates of $O x y g e n$ Evolution and Dissolution Reactions during Water Electrolysis on Iridium. Angewandte Chemie International Edition 2018, 57 (9), 2488-2491. https:// doi.org/ 10.1002/ anie.201709652.

(8) Claudel, F.; Dubau, L.; Berthomé, G.; Sola-Hernandez, L.; Beauger, $C$.; Piccolo, L.; M aillard, F., D egradation M echanisms of $O$ xygen Evolution Reaction Electrocatalysts: A Combined Identical-Location Transmission Electron M icroscopy and X-ray Photoelectron Spectroscopy Study. ACS Catal. 2019, 9 (5), 4688-4698. https:// doi.org/ 10.1021/ acscatal.9b00280.
(9) Kasian, O .; Geiger, S.; Li, T .; Grote, J. P.; Schweinar, K.; Zhang, S.; Scheu, C.; Raabe, D.; Cherevko, S.; Gault, B.; Mayrhofer, K. J. J., Degradation of iridium oxides via oxygen evolution from the lattice: Correlating atomic scale structure with reaction mechanisms. Energy and Environmental Science 2019, $12 \quad$ (12), 3548-3555. https:// doi.org/ 10.1039/ c9ee01872g.

(10) Saveleva, V. A.; Wang, L.; Kasian, O .; Batuk, M .; H adermann, J.; Gallet, J. J.; Bournel, F.; Alonso-Vante, N.; O zouf, G.; Beauger, C.; M ayrhofer, K. J. J.; Cherevko, S.; G ago, A. S.; Friedrich, K. A.; Zafeiratos, S.; Savinova, E. R., Insight into the M echanisms of H igh Activity and Stability of I ridium Supported on Antimony-D oped T in O xideAerogel for Anodes of Proton Exchange M embrane W ater Electrolyzers. ACS C atal. 2020, 10 (4), 2508-2516. https:// doi.org/ 10.1021/ acscatal.9b04449.

(11) Chen, G.; Li, J.; L v, H.; Wang, S.; Zuo, J.; Zhu, L., M esoporous coxsn $(1-x) 02$ as an efficient oxygen evolution catalyst support for spe water electrolyzer. Royal Society Open Science 2019, 6 (4). https:// doi.org/ 10.6084/ m9.figshare.

(12) Li, X.; Pletcher, D.; Walsh, F. C., Electrodeposited lead dioxide coatings. Chem. Soc. Rev. 2011, 40 (7), 3879-3894. https:// doi.org/ 10.1039/ c0cs00213e.

(13) Lei, Z.; Wang, T .; Zhao, B.; Cai, W ;; Liu, Y.; Jiao, S.; Li, Q .; C ao, R.; Liu, M ., Recent Progress in Electrocatalysts for Acidic W ater $O$ xidation. Adv. Energy Mater. 2020, 10 (23), 1-18. https:// doi.org/ 10.1002/ aenm.202000478.

(14) Bonke, S. A.; Wiechen, M .; H ocking, R. K.; Fang, X.-Y.; Lupton, D. W.; MacFarlane, D. R.; Spiccia, L., Electrosynthesis of Highly Transparent Cobalt $O$ xide Water 0 xidation Catalyst Films from Cobalt Aminopolycarboxylate Complexes. ChemSusChem 2015, 8 (8), 13941403. https:// doi.org/ 10.1002/ cssc.201403188.

(15) Bonke, S. A.; Bond, A. M.; Spiccia, L.; Simonov, A. N., Parameterization of $W$ ater Electrooxidation $C$ atalyzed by $M$ etal $O$ xides Using Fourier Transformed Alternating Current Voltammetry. J. Am. Chem. Soc. 2016, 138 (49), 16095-16104. https:// doi.org/ 10.1021/ jacs.6b10304.

(16) Liu, G.; Karuturi, S. K.; Simonov, A. N .; Fekete, M .; Chen, H .; N asiri, N .; Le, N . H.; Reddy N arangari, P.; Lysevych, M .; Gengenbach, T. R.; Lowe, A.; T an, H . H .; Jagadish, C.; Spiccia, L.; Tricoli, A., Robust Sub$\mathrm{M}$ onolayers of $\mathrm{C} 0304 \mathrm{~N}$ ano-I slands: A Highly Transparent M orphology for Efficient Water 0 xidation C atalysis. $A d v$. Energy M ater. 2016, 6 (15) , 19. https:// doi.org/ 10.1002/ aenm.201600697.

(17) Hocking, R. K.; Brimblecombe, R.; Chang, L. Y.; Singh, A.; Cheah, M. H.; Glover, C.; Casey, W. H.; Spiccia, L., Water-oxidation catalysis by manganese in a geochemical-like cycle. Nature Chemistry 2011, 3(6), 461-466. https:// doi.org/ 10.1038/ nchem.1049.

(18) Beltrán-Suito, R.; Forstner, V.; H ausmann, J. N .; M ebs, S.; Schmidt, J.; Zaharieva, I.; Laun, K.; Zebger, I.; Dau, H.; M enezes, P. W.; D riess, M ., A soft molecular 2Fe-2As precursor approach to the synthesis of nanostructured $\mathrm{FeA}$ s for efficient electrocatalytic water oxidation. Chemical $\begin{array}{llll}\text { Science } & 2020, & 11 & \text { (43), }\end{array}$ https:// doi.org/ 10.1039/D0SC 04384B.

(19) Smith, R. D.L.; Prévot, M .S.; Fagan, R. D.; Zhang, Z.; Sedach, P. A.; Siu, M. K. J.; Trudel, S.; Berlinguette, C.P., Photochemical Route for Accessing A morphous $M$ etal $O$ xide $M$ aterials for $W$ ater $O$ xidation $C$ atalysis. Science 2013, 340 (6128), 60-63. https:// doi.org/ 10.1126/ science.1233638.

(20) Chatti, M .; Glushenkov, A. M .; Gengenbach, T .; Knowles, G. P.; M endes, T. C.; Ellis, A. V.; Spiccia, L.; H ocking, R. K.; Simonov, A. N., Highly dispersed and disordered nickel-iron layered hydroxides and sulphides: Robust and high-activity water oxidation catalysts. Sustainable Energy and Fuels 2018, 2 (7), 1561-1573. https:// doi.org/ 10.1039/ c8se00129d.

(21) Trotochaud, L.; Young, S. L.; Ranney, J. K.; Boettcher, S. W., $\mathrm{N}$ ickel-I ron 0 xyhydroxide 0 xygen-Evolution Electrocatalysts: T he Role of Intentional and Incidental I ron Incorporation. J. A m. Chem. Soc. 2014, 136 (18), 6744-6753. https:// doi.org/ 10.1021/ja502379c.

(22) M cC rory, C.C.L.; Jung, S.; Ferrer, I. M .; Chatman, S. M .; Peters, J. C.; Jaramillo, T. F., Benchmarking Hydrogen Evolving Reaction and 
Oxygen Evolving Reaction Electrocatalysts for Solar Water Splitting Devices. J. Am. Chem. Soc. 2015, 137 (13), 4347-4357. https:// doi.org/ 10.1021/ja510442p.

(23) Frydendal, R.; Paoli, E. A.; Chorkendorff, I.; Rossmeisl, J.; Stephens, I. E. L., Toward an Active and Stable Catalyst for Oxygen Evolution in Acidic M edia: T i-Stabilized M nO 2. Adv. Energy M ater. 2015,

(22),

1500991

https:// doi.org/ https:// doi.org/ 10.1002/ aenm.201500991.

(24) Mondschein, J. S.; Callejas, J. F.; Read, C. G.; Chen, J. Y. C.; H older, C. F.; Badding, C. K.; Schaak, R. E., Crystalline C obalt O xide Films for Sustained Electrocatalytic Oxygen Evolution under Strongly Acidic Conditions. Chem. Mater. 2017, 29 (3), 950-957. https:// doi.org/ 10.1021/ acs.chemmater.6b02879.

(25) Van Gosen, B. S.; Verplanck, P. L.; Seal Ii, R. R.; Long, K. R.; Gambogi, J. Rare-earth elements, 18020; Reston, VA, 2017; p 44. https:// doi.org/ 10.3133/pp18020.

(26) Bloxham, L.; Cowley, A.; H an, L.; Shao, E., Pgm M arket Report. JM 2020, February, 1-48.

(27) Schulte, R. F., Platinum-G roup M etals. USGS 2018, 703, 124 125.

(28) Song, S.; Zhang, H.; M a, X.; Shao, Z.; Baker, R. T.; Yi, B., Electrochemical investigation of electrocatalysts for the oxygen evolution reaction in PEM water electrolyzers. Int. J. H ydrogen Energy 2008, 33 (19), 4955-4961. https:// doi.org/ 10.1016/ j.ijhydene.2008.06.039.

(29) Cherevko, S.; Geiger, S.; Kasian, O.; Kulyk, N.; Grote, J. P.; Savan, A.; Shrestha, B. R.; M erzlikin, S.; Breitbach, B.; Ludwig, A.; $M$ ayrhofer, K. J. J., O xygen and hydrogen evolution reactions on $\mathrm{Ru}, \mathrm{RuO} 2$, Ir, and IrO2 thin film electrodes in acidic and alkaline electrolytes: A comparative study on activity and stability. 2016, 262, 170-180. https:// doi.org/ 10.1016/ j.cattod.2015.08.014.

(30) Kasian, O .; Geiger, S.; Stock, P.; Polymeros, G .; Breitbach, B.; Savan, A.; Ludwig, A.; Cherevko, S.; M ayrhofer, K. J. J., O $n$ the O rigin of the Improved Ruthenium Stability in RuO 2 -IrO 2 Mixed Oxides. J. Electrochem. Soc. 2016, 163 (11), F3099-F3104. https:// doi.org/ 10.1149/2.0131611jes.

(31) Nikoloski, A. N .; Nicol, M. J., Addition of cobalt to lead anodes used for oxygen evolutiona literature review. Miner. Process. Extr. M etall. Rev. 2010, 31 (1) , 30-57. https:// doi.org/ 10.1080/ 08827500903404872.

(32) Schmachtel, S.; M urtomäki, L.; Aromaa, J.; Lundström, M.; Forsén, O.; Barker, M. H., Simulation of electrochemical processes during oxygen evolution on $\mathrm{Pb}-\mathrm{MnO} 2$ composite electrodes. Electrochim. Acta 2017, 245, 512-525. https:// doi.org/ 10.1016/ i.electacta.2017.04.131.

(33) M Marshall, A.T .; Sunde, S.; T sypkin, M .; T unold, R., Performance of a PEM water electrolysis cell using I rx Ruy $T$ az 02 electrocatalysts for the oxygen evolution electrode. Int. J. Hydrogen Energy 2007, 32 (13), 2320 2324. https:// doi.org/ 10.1016/i.ijhydene.2007.02.013.

(34) T unold, R.; M arshall, A.T .; Rasten, E.; T sypkin, M .; O we, L.-E.; Sunde, S., M aterials for Electrocatalysis of Oxygen Evolution Process in PEM Water Electrolysis Cells. 2010, 25 (23), 103-117. https:// doi.org/ 10.1149/1.3328515.

(35) Wu, X.; T ayal, J.; Basu, S.; Scott, K., N ano-crystalline RuxSn1$\mathrm{XO} 2$ powder catalysts for oxygen evolution reaction in proton exchange membrane water electrolysers. Int. J. Hydrogen Energy 2011, 36 (22), 14796-14804. https:// doi.org/ 10.1016/ j.ijhydene.2011.01.067.

(36) Oakton, E.; Lebedev, D.; Povia, M.; Abbott, D. F.; Fabbri, E.; Fedorov, A.; N achtegaal, M.; Copéret, C.; Schmidt, T. J., IrO 2-TiO 2: A High-Surface-Area, Active, and Stable Electrocatalyst for the 0 xygen Evolution Reaction. ACS Catal. 2017, 7 (4), 2346-2352. https:// doi.org/ 10.1021/ acscatal.6b03246.

(37) Etzi Coller Pascuzzi, M.; Goryachev, A.; H ofmann, J. P.; H ensen, E. J. M ., M n promotion of rutile T IO 2-RuO 2 anodes for water oxidation in acidic media. Appl. Catal. B Environ. 2020, 261, 118225. https:// doi.org/ 10.1016/ j.apcatb.2019.118225.

(38) Chatti, M.; Gardiner, J. L.; Fournier, M.; Johannessen, B.; Williams, T.; Gengenbach, T. R.; Pai, N .; N guyen, C.; M acFarlane, D. R.; Hocking, R. K.; Simonov, A. N., Intrinsically stable in situ generated electrocatalyst for long-term oxidation of acidic water at up to $80^{\circ} \mathrm{C}$. Nature Catal. 2019, 2 (5) , 457-465. https:// doi.org/ 10.1038/ s41929-019-0277-8.

(39) Bonke, S. A.; Abel, K. L.; Hoogeveen, D. A.; Chatti, M.; Gengenbach, T .; F ournier, M .; Spiccia, L.; Simonov, A. N ., Electrolysis of $N$ atural W aters $C$ ontaminated with $T$ ransition-M etal I ons: I dentification of A M etastable FePb-Based 0 xygen-Evolution Catalyst $O$ perating in W eakly Acidic Solutions. ChemPlusChem 2018, 83 (7), 704-710. https:// doi.org/ 10.1002/ cplu.201800020.

(40) H uynh, M .; O zel, T.; Liu, C.; Lau, E. C.; N ocera, D. G., Design of template-stabilized active and earth-abundant oxygen evolution catalysts in acid. Chemical Science 2017, 8 (7), 4779-4794. https:// doi.org/ 10.1039/ c7sc01239j.

(41) Kim, J.; Shih, P. C.; T sao, K. C.; Pan, Y. T .; Yin, X.; Sun, C. J.; Yang, $\mathrm{H} ., \mathrm{H}$ igh-Performance Pyrochlore-Type Yttrium Ruthenate Electrocatalyst for 0 xygen Evolution Reaction in Acidic Media. J. Am. Chem. Soc. 2017, 139 (34), 12076-12083. https:// doi.org/ 10.1021/ jacs.7b06808.

(42) Lin, Y.; T ian, Z.; Zhang, L.; M a, J.; Jiang, Z.; Chen, L.; Deibert, B. J.; Ge, R., Chromium-ruthenium oxide solid solution electrocatalyst for highly efficient oxygen evolution reaction in acidic media. Nature Comm. 2019, 10 (2019), 162-162. https:/ / doi.org/ 10.1038/ s41467-018-08144-3.

(43) M oreno-H ernandez, I. A.; M acfarland, C. A.; Read, C. G.; Papadantonakis, K. M .; Brunschwig, B. S.; Lewis, N. S., Crystalline nickel manganese antimonate as a stable water-oxidation catalyst in aqueous $1.0 \mathrm{M}$ H 2SO 4. Energy and Environmental Science 2017, 10 (10), 2103-2108. https:// doi.org/ 10.1039/ c7ee01486d.

(44) Shinde, A.; Jones, R. J. R.; Guevarra, D.; M itrovic, S.; BecerraStasiewicz, N.; Haber, J. A.; Jin, J.; Gregoire, J. M., H igh-T hroughput Screening for Acid-Stable 0 xygen Evolution Electrocatalysts in the ( $\mathrm{Mn}$ Co-T a-Sb) 0x Composition Space. Electrocatal. 2015, 6 (2), 229-236. https:// doi.org/ 10.1007/s12678-014-0237-7.

(45) Brookins, D. G., Geochemical behavior of antimony, arsenic, cadmium and thallium: EhpH diagrams for $25^{\circ} \mathrm{C}, 1$-bar pressure. Chem. Geol. 1986, 54 (3-4), 271-278. https:// doi.org/ 10.1016/0009$\underline{2541(86) 90141-5}$.

(46) Allen, J. P.; C arey, J. J.; W alsh, A.; Scanlon, D. O .; W atson, G. W., Electronic structures of antimony oxides. J. Phys. Chem. C 2013, 117(28), 14759-14769. https:// doi.org/ 10.1021/jp4026249.

(47) O uni, B.; Haj Lakhdar, M.; Boughalmi, R.; Larbi, T.; Boukhachem, A.; M adani, A.; Boubaker, K.; Amlouk, M ., Investigation of electrical and dielectric properties of antimony oxide (Sb204) semiconductor thin films for TCO and optoelectronic applications. J. N on$\begin{array}{lllll}\text { Cryst. Solids } & \text { 2013, } 367 \text { (1), }\end{array}$ https:// doi.org/ 10.1016/j.jnoncrysol.2013.02.006.

(48) $\mathrm{He}$, J.; Wei, Y.; Zhai, T.; Li, H., Antimony-based materials as promising anodes for rechargeable lithium-ion and sodium-ion batteries. Materials Chemistry Frontiers 2018, 2 (3), 437-455. https:// doi.org/ 10.1039/ c7qm00480j.

(49) Vesborg, P. C. K .; Jaramillo, T. F., Addressing the terawatt challenge: Scalability in the supply of chemical elements for renewable energy. RSC Advances 2012, 2 (21), $7933-7947$. https:// doi.org/ 10.1039/ c2ra20839c.

(50) Chen, B.; Wang, S.; Liu, J.; H uang, H .; Dong, C.; H e, Y.; Yan, W.; Guo,Z.; Xu, R.; Yang, H ., Corrosion resistance mechanism of a novel porous $\mathrm{Ti} / \mathrm{Sn}-\mathrm{Sb}-\mathrm{RuOx} / \mathrm{\beta}-\mathrm{PbO} 2$ anode for zinc electrowinning. Corros. Sci. 2018, 144(August), 136-144. https:// doi.org/ 10.1016/ j.corsci.2018.08.049.

(51) Liu, J.; Wang, T.; Chen, B., Effect of M olar Ratio of Ruthenium and Antimony on Corrosion M echanism of Ti/Sn-Sb-RuO x Electrode for Zinc Electrowinning. J. Electrochem. Soc. 2019, 166 (15), D798-D 803. https:// doi.org/ 10.1149/2.0511915jes.

(52) Zhou, L.; Shinde, A.; M ontoya, J. H.; Singh, A.; Gul, S.; Yano, J.; Ye, Y.; Crumlin, E. J.; Richter, M . H .; Cooper, J. K.; Stein, H. S.; H aber, J. A.; Persson, K. A.; Gregoire, J. M., Rutile Alloys in the M n-Sb-O System Stabilize M n3+ to Enable Oxygen Evolution in Strong Acid. ACS Catal. 2018, 8 (12) , 10938-10948. https:// doi.org/ 10.1021/ acscatal.8b02689.

(53) Moreno-Hernandez, I. A.; Brunschwig, B. S.; Lewis, N. S., Crystalline nickel, cobalt, and manganese antimonates as electrocatalysts for 
the chlorine evolution reaction. Energy and Environmental Science 2019, 12 (4) , 1241-1248. https:// doi.org/ 10.1039/ c8ee03676d.

(54) Evans, T. A.; Choi, K. S., Electrochemical Synthesis and Investigation of Stoichiometric, Phase - Pure C OSb2O 6 and M nSb2O 6 Electrodes for the Oxygen Evolution Reaction in Acidic Media. ACS Applied Energy M aterials2020. https:// doi.org/ 10.1021/ acsaem.0c00526.

(55) Yang, J. K.; Liang, B.; Zhao, M . J.; Gao, Y.; Zhang, F.C.; Zhao, H . $L$., R eference of $T$ emperature and $T$ ime during tempering process for nonstoichiometric FTO films. Scientific Reports 2015, 5, 1-6. https:// doi.org/ 10.1038/ srep15001.

(56) Spöri, C.; Kwan, J. T. H.; Bonakdarpour, A.; Wilkinson, D. P.; Strasser, P., The Stability Challenges of Oxygen Evolving Catalysts: Towards a Common Fundamental Understanding and Mitigation of Catalyst D egradation. Angewandte Chemie - International Edition 2017, 56 (22), 5994-6021. https:// doi.org/ 10.1002/ anie.201608601.

(57) Costentin, C.; N ocera, D. G., Self-healing catalysis in water. Proc. Natl. Acad. Sci. U.S.A. 2017, 114 (51), 13380-13384. https:// doi.org/ 10.1073/ pnas.1711836114.

(58) Mohammadi, M. R.; Loos, S.; Chernev, P.; Pasquini, C.; Zaharieva, I.; G onzález-Flores, D.; Kubella, P.; Klingan, K.; Smith, R. D. L.; Dau, H., Exploring the Limits of Self-Repair in Cobalt Oxide Films for Electrocatalytic Water Oxidation. ACS Catal. 2020, 10 (14), 7990-7999. https:// doi.org/ 10.1021/ acscatal.0c01944.

(59) H uynh, M.; Bediako, D. K.; N ocera, D. G ., A Functionally Stable $M$ anganese 0 xide 0 xygen Evolution C atalyst in Acid. JACS 2014, (136), 6002-6010. https:// doi.org/ 10.1021/ja413147e.

(60) C. D. Wanger, W. M. R. L. E. D. J. F. M .; Muilenberg, G. E., Handbook of X-ray Photoelectron Spectroscopy. Perkin-E/mer Corp. 1979.

(61) Matthew, J., Surface analysis by Auger and x-ray photoelectron spectroscopy. D. Briggs and J. T . G rant (eds). IM Publications, C hichester, UK and SurfaceSpectra, M anchester, UK, 2003. 900 pp., ISBN 1-90101904-7, 900 pp. Surf. Interface Anal. 2004, 36 (13), 1647-1647. https:// doi.org/ 10.1002/ sia.2005.

(62) Biesinger, M. C.; Payne, B. P.; Grosvenor, A. P.; Lau, L. W. M.; Gerson, A. R.; Smart, R. S. C., Resolving surface chemical states in XPS analysis of first row transition metals, oxides and hydroxides: $\mathrm{Cr}, \mathrm{Mn}, \mathrm{Fe}, \mathrm{Co}$ and Ni. Appl. Surf. Sci. 2011, 257 (7), 2717-2730. https:// doi.org/10.1016/j.apsusc.2010.10.051.

(63) Sabri, M.; King, H. J.; Gummow, R. J.; Lu, X.; Zhao, C.; O elgemöller, M.; Chang, S. L. Y.; H ocking, R. K., Oxidant or C atalyst for Oxidation? A Study of H ow Structure and Disorder Change the Selectivity for Direct versus Catalytic Oxidation M ediated by $M$ anganese( III,IV) Oxides. Chem. Mater. 2018, 30 (22), 8244-8256. https:// doi.org/ 10.1021/ acs.chemmater.8b03661.

(64) H ocking, R. K.; Gummow, R. J.; King, H. J.; Sabri, M .; Kappen, P.; Dwyer, C.; Chang, S. L. Y., Direct Formation of 2D-M nOx under Conditions of Water 0 xidation Catalysis. ACS Applied Nano Materials 2018, 1 (4) , 1603-1611. https:// doi.org/ 10.1021/ acsanm.8b00095.

(65) King, H. J.; Fournier, M.; Bonke, S. A.; Seeman, E.; Chatti, M .; Jumabekov, A. N .; Johannessen, B.; Kappen, P.; Simonov, A. N .; H ocking, R. K., Photon-Induced, $T$ imescale, and Electrode Effects $C$ ritical for the in Situ X-ray Spectroscopic Analysis of Electrocatalysts: T he W ater 0 xidation Case. J. Phys. Chem. C 2019, 123 (47), 28533-28549. https:// doi.org/ 10.1021/acs.jpcc.9b06944.

(66) Vincent, $H_{\text {.; }}$ T urrillas, $X_{\text {.; }}$ Rasines, I., A novel structural type of hexagonal closest packing the ternary oxide, $\beta-M n S b 206$. Mater. Res. Bull. 1987, 22 (10), 1369-1379. https:// doi.org/10.1016/00255408(87) 90302-3.

(67) Donaldson, J. D.; Kjekshus, A.; Nicholson, D. G.; Rakke, T., Properties of Sb-compounds with rutile like structures. Acta Chemica $\begin{array}{llll}\text { Scandinavica } & \text { A } & \text { 803-809. }\end{array}$ https:// doi.org/ 10.3891/acta.chem.scand.29a-0803.

(68) M organ, D. J., Resolving ruthenium: XPS studies of common ruthenium materials. Surf. Interface Anal. 2015, 47 (11), 1072-1079. https:// doi.org/ 10.1002/ sia.5852.
(69) Kropáček, V.; Krs, M.; Bucha, V., Magnetic properties of natural M n-oxides. Studia Geophysica et Geodaetica 1975, 19 (3), 261-274. https:// doi.org/ 10.1007/ BF01614255.

(70) Ganguly, S.; Kabir, M.; Sanyal, B.; M ookerjee, A., U nusual structure and magnetism in manganese oxide nanoclusters. Physical Review $B$ - Condensed Matter and Materials Physics 2011, 83 (2), 2-5. https:// doi.org/ 10.1103/PhysRevB.83.020411.

(71) Ghadge, S. D.; Velikokhatnyi, O I.; D atta, M . K.; Shanthi, P. M .; Tan, S.; Kumta, P. N ., Computational and Experimental Study of Fluorine D oped $\left(\mathrm{M} \mathrm{n}_{1-\mathrm{x}} \mathrm{N} \mathrm{b}_{\mathrm{x}}\right) \mathrm{O}_{2} \mathrm{~N}$ anorod Electrocatalysts for A cid-M ediated $\mathrm{O}$ xygen Evolution Reaction. ACS Applied Energy M aterials 2020, 3 (1), 541-557. https:// doi.org/ 10.1021/ acsaem.9b01796.

(72) Xiao, B. B.; Jiang, X. B.; Jiang, Q ., D ensity functional theory study of oxygen reduction reaction on $\mathrm{Pt} / \mathrm{Pd} 3 \mathrm{Al}$ (111) alloy electrocatalyst. $P C C P$ 2016, 18 (21), 14234-14243. https:// doi.org/ 10.1039/ c6cp01066k.

(73) G reeley, .; N ørskov, J. K., Electrochemical dissolution of surface alloys in acids: Thermodynamic trends from first-principles calculations. Electrochim. Acta 2007, 52 (19), 5829-5836. https:// doi.org/ 10.1016/i.electacta.2007.02.082.

(74) Russell, A. E., Electrocatalysis: Theory and experiment at the interface. PCCP 2008, 10 (25), 3607-3608. https:// doi.org/ 10.1039/ b808799g.

(75) LV, X.; Wei, W.; Wang, H .; H uang, B.; D ai, Y., M ultifunctional electrocatalyst PtM with low Pt loading and high activity towards hydrogen and oxygen electrode reactions: A computational study. Appl. Catal. B Environ. 2019, 255,

https:// doi.org/10.1016/j.apcatb.2019.05.045.

(76) Wang, L.; Roudgar, A.; Eikerling, M., Ab initio study of stability and site-specific oxygen adsorption energies of Pt nanoparticles. J. Phys. Chem. C 2009, 113 (42), 17989-17996. https:// doi.org/ 10.1021/jp900965q.

(77) Kadakia, K.; D atta, M .K.; Velikokhatnyi, O I.; Jampani, P.; Park, S. K.; Saha, P.; Poston, J. A.; M anivannan, A.; Kumta, P. N., N ovel $(\mathrm{Ir}, \mathrm{Sn}, \mathrm{N} \mathrm{b}) \mathrm{O}_{2}$ anode electrocatalysts with reduced noble metal content for PEM based water electrolysis. 2012, 37, 3001-3013. https:// doi.org/ 10.1016/j.ijhydene.2011.11.055.

(78) Luo, Y. R., Comprehensive $\mathrm{H}$ andbook of Chemical Bond Energies. CRC Press, Boca Raton 2007.

(79) Chen, J.; Selloni, A., Electronic states and magnetic structure at the $\mathrm{CO}_{3} \mathrm{O}_{4}(110)$ surface: A first-principles study. Physical Review $B$ Condensed Matter and Materials Physics 2012, 85 (8), 1-9. https:// doi.org/ 10.1103/PhysRevB.85.085306.

(80) Tasker, P. W., The stability of ionic crystal surfaces. Journal of Physics C: Solid State Physics 1979, 12 (22), 4977-4984. https:// doi.org/ 10.1088/ 0022-3719/12/22/036.

(81) Vaz, C.A. F.; Wang, H.Q ; Ahn, C. H .; Henrich, V. E.; Baykara, M . Z.; Schwendemann, T . C.; Pilet, N .; Albers, B. J.; Schwarz, U. D .; Zhang, L. H.; Zhu, Y.; Wang, J.; Altman, E. I., Interface and electronic characterization of thin epitaxial $\mathrm{C}_{3} \mathrm{O}_{4}$ films. Surf. Sci. 2009, 603(2), 291297. https:// doi.org/ https:// doi.org/ 10.1016/i.susc.2008.11.022.

(82) Ong, S. P.; Wang, L.; Kang, B.; Ceder, G., Li - Fe - P - 02 phase diagram from first principlescalculations. Chem. Mater. 2008, 20(5), 17981807. https:// doi.org/ $10.1021 / \mathrm{cm} 702327 \mathrm{~g}$.

(83) Eskandrani, A. A.; Ali, S. M.; Al-Otaibi, H. M., Study of the oxygen evolution reaction at strontium palladium perovskite electrocatalyst in acidic medium. International Journal of M olecular Sciences 2020, 21 (11). https:// doi.org/ 10.3390/ijms21113785.

(84) Suermann, M.; Schmidt, T. J.; Büchi, F. N., Comparing the kinetic activation energy of the oxygen evolution and reduction reactions. Electrochim. Acta 2018, 281, 466-471. https:// doi.org/ https:// doi.org/ 10.1016/ j.electacta.2018.05.150. 